\title{
The role of adipose tissue in cardiovascular health and disease
}

\author{
Evangelos K. Oikonomou ${ }^{1}$ and Charalambos Antoniades ${ }^{1 *}$ \\ ${ }^{1}$ Division of Cardiovascular Medicine, Radcliffe Department of Medicine, University of Oxford, Oxford, \\ UK. \\ e-mail: antoniad@well.ox.ac.uk
}

Abstract | Accumulating knowledge on the biology and function of the adipose tissue has led to a major shift in our understanding of its role in health and disease. The adipose tissue is now recognized as a crucial regulator of cardiovascular health, through the secretion of several bioactive products, including adipocytokines, microvesicles, and gaseous messengers, with a wide range of endocrine and paracrine effects on the cardiovascular system. The adipose tissue function and secretome are tightly controlled by complex homeostatic mechanisms and local cell-cell interactions, which can become dysregulated in obesity. Systemic or local inflammation and insulin resistance lead to a shift in the adipose tissue secretome from anti-inflammatory and anti-atherogenic towards a pro-inflammatory and pro-atherogenic profile. Moreover, the interplay between the adipose tissue and the cardiovascular system is bidirectional, with vascular-derived and heart-derived signals directly affecting adipose tissue biology. In this Review, we summarize the current knowledge on the biology and regional variability of adipose tissue in humans, deciphering the complex molecular mechanisms controlling the crosstalk between the adipose tissue and the cardiovascular system, and their possible clinical translation. In addition, we highlight the latest developments in adipose tissue imaging for cardiovascular risk stratification, and discuss how therapeutic targeting of the adipose tissue can improve prevention and treatment of cardiovascular disease.

\section{Introduction}

Cardiovascular disease (CVD) remains a leading cause of morbidity and mortality despite substantial advances in risk stratification, prevention, and treatment. ${ }^{1}$ Obesity, traditionally defined as a $\mathrm{BMI} \geq 30$ 
$\mathrm{kg} / \mathrm{m}^{2}$, is an established cardiovascular risk factor, ${ }^{2}$ predisposing to a range of cardiometabolic abnormalities. ${ }^{3}$ However, expanding knowledge on the role of the adipose tissue in CVD pathogenesis has revealed a more complex landscape than previously thought. Large-scale epidemiological studies have questioned the exact nature of the association between BMI and adverse outcomes, suggesting an "obesity paradox", namely the paradoxical survival benefit observed among overweight or even obese individuals compared with their normal-weight counterparts in the general population or in those with chronic diseases. ${ }^{4,5}$ Moreover, the adipose tissue has striking biological variability depending on its location and metabolic state, affecting the individual's overall cardiometabolic risk. ${ }^{6-}$ ${ }^{8}$ Although anthropometric indices such as the waist-to-hip ratio (WHR) were developed to capture variations in adipose tissue distribution, ${ }^{9}$ these parameters only provide information on adipose tissue expansion and do not take into account the dynamic nature of the adipose tissue as an endocrine organ. ${ }^{9-11}$ The notion of the adipose tissue as a "biochemical factory" is not a recent one, ${ }^{10}$ but the importance of the adipose tissue in cardiovascular health and disease remains the topic of extensive research. As our knowledge on adipose tissue biology continues to expand, the adipose tissue is increasingly being recognised as a crucial regulator of cardiovascular health and disease and as a host of both diagnostic biomarkers and promising therapeutic targets.

In this Review, we present the most recent advances in the past decade in the field of adipose tissue biology and highlight how this knowledge can lead to clinical breakthroughs in cardiovascular diagnostics and therapeutics. First, we review the anatomy, composition, and biology of different adipose tissue depots in both health and disease. We discuss the biological and phenotypic heterogeneity of the adipose tissue and its importance in cardiometabolic health, with a particular emphasis on the role of "dysfunctional" adipose tissue in CVD pathogenesis. We then describe the bidirectional nature of the interactions between the adipose tissue and the cardiovascular system in humans, focusing on the potential role of this crosstalk in obesity-related cardiovascular complications. Next, we review the current state-of-the-art techniques for studying the quality and 
quantity of human adipose tissue, and finally highlight the potential of the adipose tissue as a target in future CVD therapeutics.

\section{Adipose tissue in health and disease}

\section{Structure, anatomy, and biology}

The adipose tissue in the human body can be broadly divided into two main anatomical depots, visceral adipose tissue (VAT) and subcutaneous adipose tissue (SAT). ${ }^{6,12}$ VAT in turn can be classified on the basis of its anatomical location as intrathoracic, abdominal, etc., and intrathoracic adipose tissue can be further classified as epicardial adipose tissue (EAT) and pericardial adipose tissue (PAT) on the basis of its location within or outside the human pericardium, respectively ${ }^{13}$. The importance of this classification is highlighted by studies revealing distinct transcriptomic and proteomic profiles between different adipose tissue depots, ${ }^{7,14,15}$ as well as epidemiological studies that reveal a close link between VAT expansion and cardiometabolic risk, as opposed to the neutral or even cardioprotective profile of SAT. ${ }^{6}$ However, regional biological variability has also been described within the same depots. For instance, when compared with gluteal SAT, abdominal SAT has a distinct transcriptomic signature, which resembles that of VAT depots. ${ }^{16}$ Substantial variability exists even within the abdominal SAT, with deep SAT (below Scarpa's fascia) exhibiting a metabolic phenotype closer to that of VAT, which is more closely associated with insulin resistance and cardiometabolic risk, compared with superficial SAT. ${ }^{8}$ Similar regional heterogeneity has been described in EAT, with distinct transcriptomic signatures in the peri-ventricular, peri-atrial, and peri-coronary sites. ${ }^{17}$

Based on its phenotype, functional role, and gene expression profile, the adipose tissue can be further classified as white or brown. White adipose tissue (WAT) represents most of the adipose tissue mass in humans, whereas brown adipose tissue (BAT) accounts for $\sim 4.3 \%$ of the total fat mass in adults and is located in several regions, predominantly in the interscapular and supraclavicular area. ${ }^{18} \mathrm{An}$ inducible form of BAT, namely beige adipose tissue (also known as brite adipose tissue), can be found interspersed in WAT depots and occurs in response to cold exposure and pharmacological 
modulation of WAT. ${ }^{19,20}$ Although BAT or beige adipose tissue activation is traditionally linked to thermoregulatory thermogenesis, ${ }^{18}$ this activation might also have an important role in promoting weight loss and insulin sensitivity. ${ }^{21}$

Although adipocytes account for most of the volume of a given adipose tissue depot, being responsible for energy storage in the form of triglycerides, several other cell types exist in the stromal fraction of the adipose tissue. ${ }^{7,22}$ These cell types include inflammatory cells, such as macrophages, ${ }^{23}$ lymphocytes, ${ }^{24}$ and eosinophils, ${ }^{25}$ fibroblasts, pre-adipocytes, vascular cells that form the adipose tissue microvasculature, ${ }^{7}$ as well as multipotent mesenchymal stem-like cells known as adiposederived stromal or stem cells. ${ }^{26}$ Most adipose tissue-resident cells produce and secrete adipocytokines and other mediators that exert autocrine, paracrine, and/or endocrine effects on neighbouring cells or remote tissues and organs. ${ }^{27}$ Of note, the composition of the adipose tissue secretome is largely depot-specific, and can also be affected by systemic and local factors linked to inflammation, insulin resistance, and obesity. ${ }^{23}$ For instance, analysis of adipose tissue-resident cells from different depots has revealed distinct patterns, with visceral adipose-derived stem cells secreting higher levels of proinflammatory factors, such as IL-6 and CC motif chemokine 2 (CCL2; also known as MCP1), and lower levels of anti-inflammatory mediators such as adiponectin and IL-10 compared with subcutaneous adipose-derived stem cells. ${ }^{7}$

\section{Research models on adipose tissue biology}

Animal models, including rodents, have traditionally been used to study the biological mechanisms of obesity-related cardiometabolic disease. ${ }^{28}$ However, despite many similarities between the adipose tissue of humans and rodents, there are also substantial disparities. Differences in regulation of lipolysis (for example, $\alpha 2$-adrenergic receptors and natriuretic peptides regulate lipolysis in humans but not in rodents), the absence of a layer equivalent to human deep SAT or omental adipose tissue, as well as differences in adipose tissue distribution (which preclude the development of translational tools to assess the importance of adipose tissue distribution $)^{28}$, are important limitations in the 
translation of findings from animal studies to humans, highlighting the need for new translational models to investigate the association between adipose tissue and CVD.

\section{Adipose tissue remodelling}

Obesity, insulin resistance, diabetes mellitus, and inflammation are all associated with a shift in the phenotype and biology of the adipose tissue. ${ }^{29}$ The exact nature and degree of these changes are critical in mediating the protective or adverse effects of adipose tissue on CVD pathogenesis. In response to excessive caloric intake, the adipose tissue expands through an increase in adipocyte numbers (hyperplasia) and/or size (hypertrophy). ${ }^{30,31}$ Adipose tissue hyperplasia through mobilization of progenitor cells is traditionally considered as a healthy mechanism of adipose tissue expansion, compared with adipocyte hypertrophy that can lead to dysfunctional, lipid-laden adipocytes, adipose tissue inflammation, oxidative stress, and eventual adipocyte death. ${ }^{32}$ However, adipose tissue depots differ in their adipogenic capacity. For example, the limited adipogenic capacity of the SAT might promote fat storage in ectopic, visceral depots, predisposing to systemic metabolic complications. ${ }^{33}$

In obesity and many chronic diseases (such as diabetes mellitus and atherosclerosis) the adipose tissue is infiltrated by increasing populations of inflammatory cells, ${ }^{34,35}$ such as lymphocytes (including T-helper type 1 (Th1) cells and B cells), neutrophils, macrophages, and mast cells, whereas the population of eosinophils, Th2 cells, and regulatory T cells remains constant or decreases..$^{34,36}$ Macrophages, the predominant inflammatory cells in adipose tissue, exhibit a range of phenotypes, ranging from $\mathrm{M} 1$ pro-inflammatory to $\mathrm{M} 2$ anti-inflammatory phenotypes. ${ }^{37,38}$ In lean adipose tissue, M2 macrophages predominate as a result of Th2-type cytokines released by Th2 cells and eosinophils. By contrast, in obesity and metabolic disease, adipose tissue infiltration by cells producing Th1cytokines (such as IFN $\gamma$ ) shifts the macrophage phenotype towards the M1 type. ${ }^{29,39} \mathrm{M} 1$ macrophages have also been implicated in the regulation of adipose tissue expansion and ectopic fat deposition through secretion of platelet-derived growth factor- $\beta$, which activates pericytes and promotes neoangiogenesis. ${ }^{40}$ 
Adipose tissue expansion in obesity is also associated with capillary rarefaction, resulting in reduced delivery of nutrients and oxygen to the adipose tissue, and eventually to adipose tissue dysfunction and insulin resistance. ${ }^{41}$ Endothelial cell activation, characterised by increased expression of adhesion molecules such as P-selectin and E-selectin that promote inflammatory cell infiltration, and vasomotor dysfunction of the adipose tissue vasculature have also been implicated in the pathogenesis of dysfunctional adipose tissue. ${ }^{42}$ The resulting hypoxia-induced increase in hypoxiainducible factor $1 \alpha$ can further promote adipose tissue fibrosis, which is more prevalent in VAT and SAT from obese individuals. ${ }^{43}$ More recent studies have also implicated lymphatic vessel dysfunction in adipose tissue dysfunction, with evidence showing that leakage of lipid-rich lymph from dysfunctional lymphatic vessels, especially in visceral sites, can stimulate adipogenesis, adipose tissue hypertrophy, and ectopic adipose tissue expansion. ${ }^{44}$

Obesity-related metabolic disease is also associated with changes in the balance between the relatively "protective" BAT and beige adipose tissue phenotype and the "deleterious" WAT phenotype. In mice, both BAT transplantation and WAT "beiging" - a term describing the proliferation in WAT of adipocytes expressing mitochondrial brown fat uncoupling protein 1 (UCP1) - are associated with weight loss and improved insulin resistance. ${ }^{21,45}$ Similarly, in humans, obesity is associated with lower BAT volume ${ }^{46}$ while decreased expression of UCP1 in human EAT is related to increased adipose tissue oxidative stress and dysfunction. ${ }^{47}$ The effects of BAT on insulin resistance and remote tissues are not only a result of the increased metabolic activity and thermogenic capacity of BAT, but also the release of BAT-specific adipokines (termed "batokines") which exert beneficial autocrine as well as paracrine and endocrine effects on peripheral tissues, including the cardiovascular system. ${ }^{20}$ Nevertheless, owing to substantial inter-species differences in the molecular signature and regulation of brown and beige adipocyte formation, ${ }^{19}$ our understanding of the role and full therapeutic potential of BAT and beige adipose tissue in humans remains limited.

Finally, further to the changes in adipose tissue composition, obesity, insulin resistance, and diabetes mellitus are also linked to changes in the secretory and biochemical profile of adipose tissue, 
consistent with a shift towards a more pro-inflammatory phenotype (Table 1$).{ }^{48}$ For instance, obesityrelated insulin resistance is linked to higher circulating levels of retinol-binding protein 4 (RBP4), ${ }^{49}$ visfatin, ${ }^{50}$ chemerin, ${ }^{51}$ vaspin, ${ }^{52}$ resistin, ${ }^{53}$ and to lower levels of omentin $1^{54}$ and adiponectin. ${ }^{55}$ However, adipokine expression levels in specific adipose tissue depots might not necessarily correlate with the adipokine levels in circulation, ${ }^{56}$ suggesting the existence of complex mechanisms that regulate the biology and secretome of the adipose tissue. As discussed below, this concept of adipokine signalling is central to the adipo-vascular axis, ${ }^{57}$ and provides a mechanistic link between adipose tissue biology and CVD pathogenesis.

\section{BMI as a risk factor: the obesity paradox}

On the basis of the results of a large-scale meta-analysis including $>30$ million individuals, the association between BMI and all-cause mortality in the general population can be described as $\mathrm{U}$ shaped or J-shaped. ${ }^{4}$ The higher risk observed in certain occasions among individuals with low-tonormal BMI values compared with those in the overweight group, especially for short-term (5-10 years) mortality, might be attributed to the effects of chronic diseases (such as cancer and chronic kidney disease) that are associated with a hypercatabolic state..$^{58}$ Inherent limitations of BMI to capture adipose tissue distribution and body composition might also contribute to this paradox, suggesting that the obesity paradox is essentially a "BMI paradox".$^{58}$ In an analysis of $>130,000$ UK Biobank participants (aged 60-69 years, without active smoking or disease-associated weight loss, with a follow-up of $\leq 8.3$ years), no significant difference was observed in the risk of death between normal-weight and overweight individuals ${ }^{9}$. However, within each group, higher WHR was significantly associated with an excess mortality, highlighting the limitations of BMI in defining central adiposity. ${ }^{9}$

In some chronic disease states, including patients with heart failure or with metabolic abnormalities, the paradoxical survival benefit of overweight and/or obese individuals compared with their normal-weight counterparts is even more pronounced, with multiple studies showing an inverse association between $\mathrm{BMI}$ and adverse events. ${ }^{5,59}$ However, the observed associations are not 
necessarily causal in nature. The adipose tissue can respond to inflammatory and cachexia-related signals in chronic disease states, leading to increased lipolysis and volume reduction. ${ }^{58,60}$ In addition, differences in lean body mass (BMI does not differentiate fat from lean body mass) and cardiorespiratory fitness might also have a confounding role, possibly explaining the paradoxical survival benefit observed with increasing BMI levels, particularly among patients with heart failure $\mathrm{fl}^{61,62}$. Taken together, these paradoxical and apparently contradictory findings reinforce the view that we should look beyond the adipose tissue volume to understand better the mechanisms linking adipose tissue with overall cardiometabolic health.

\section{Adipose tissue and the cardiovascular system}

Adipose tissue expansion and dysfunction lead to CVD through a series of interrelated direct and indirect mechanisms. Obesity is known to induce hypertension, possibly through mechanical compression of the kidneys owing to VAT expansion, activation of the sympathetic nervous system activity and the renin-angiotensin-aldosterone system (RAAS) independently of aldosterone, and a mild natriuretic peptide deficiency. ${ }^{63,64}$ Obesity-related adipose tissue inflammation and resulting dysfunction are also crucial components of insulin resistance, which can lead to type 2 diabetes mellitus and its well-known deleterious effects on microvascular and macrovascular function. ${ }^{38}$ Dysfunctional adipose tissue might also promote thrombosis through increased isoprostane and tissue factor production, as well as by inducing platelet insulin resistance and activation. ${ }^{65}$ In addition to these indirect mechanisms, the adipose tissue exerts direct effects on the cardiovascular system through the secretion of a wide range of bioactive adipocytokines, including adipokines (such as adiponectin) and pro-inflammatory cytokines, ${ }^{56}$ as well as other products, including microRNAs, ${ }^{66}$ microvesicles, ${ }^{67}$ inorganic molecules such as hydrogen sulphide $\left(\mathrm{H}_{2} \mathrm{~S}\right),{ }^{68}$ and fatty acid metabolites. ${ }^{69}$ These molecules can exert autocrine effects on the adipose tissue itself, but can also regulate the biology of adjacent or even distant tissues through endocrine, paracrine, ${ }^{70}$ and vasocrine mechanisms (Figure 1$)^{71}$ 


\section{Effects on the vascular wall}

Vascular tone, inflammation, vascular smooth muscle cell (VSMC) migration, endothelial function, and vascular redox state are all under the regulation of adipose tissue-derived products including adipocytokines (Figure 2). While most depots can exert endocrine effects, perivascular adipose tissue (PVAT) is now recognised as a critical regulator of vascular function given its anatomical proximity to the vascular wall, which facilitates a range of direct, paracrine effects. ${ }^{70}$

The adipose tissue regulates the vascular tone in healthy conditions through the release of molecules with vasorelaxant properties, such as adiponectin, which induces $5^{\prime}$ adenosine monophosphate-activated protein kinase (AMPK) or RAC-alpha serine/threonine-protein kinase (AKT)-mediated endothelial nitric oxide synthase (eNOS) phosphorylation, ${ }^{56,72} \mathrm{H}_{2} \mathrm{~S}$, which causes activation of ATP-regulated potassium channels, ${ }^{68}$ and palmitic acid methyl ester (PAME), which activates voltage-gated potassium channels. ${ }^{69}$ The decreased production of all these mediators in obesity and insulin resistance might contribute to obesity-related vasomotor dysfunction. ${ }^{11,70,73} \mathrm{~A}$ 2018 study suggests that PVAT in particular is involved in the circadian regulation of blood pressure through aryl hydrocarbon receptor nuclear translocator-like protein 1 (also known as BMAL1) in brown adipocytes, which regulates local angiotensinogen production ${ }^{74}$ and further contributes to the uptake and metabolism of vasoconstrictors such as noradrenaline. ${ }^{75}$ Furthermore, experimental evidence from mice suggest that reactive oxygen species (ROS), such as NOX4-derived hydrogen peroxide from BAT, can induce cyclic GMP-dependent protein kinase $\mathrm{G}$ type- $\alpha$ activation, resulting in reduced vascular contractility. ${ }^{76}$

Adipose tissue-derived molecules further regulate the vascular redox state, and increased vascular oxidative stress has been associated with accelerated biological senescence and adverse clinical outcomes. ${ }^{77} \mathrm{NADPH}$ is a potent source of superoxide radicals and signalling ROS in the vascular wall ${ }^{48,78,79}$. The activity of certain isoforms of NADPH-oxidase (for example, NOX1 and NOX2) is inhibited by antioxidant adipokines such as adiponectin and omentin 1 (by preventing the activation 
and membrane translocation of RAC1 and by downregulating $\mathrm{p} 22^{\text {phox }}$ regulatory protein), ${ }^{56,73}$ but promoted by pro-oxidant adipokines such as leptin and resistin, thereby contributing to atherogenesis. $^{48}$ Uncoupling of eNOS through reduced bioavailability of its cofactor tetrahydrobiopterin $\left(\mathrm{BH}_{4}\right)$ is another crucial mechanism contributing to deleterious superoxide production. ${ }^{80}$ While adiponectin and other adipokines such as $\mathrm{C} 1 \mathrm{q} /$ tumor necrosis factor-related protein 9 (CTRP) promote eNOS phosphorylation through activation of the AMPK pathway and improved eNOS coupling, ${ }^{56,81,82}$ chemerin has opposing effects, promoting eNOS uncoupling and decreasing nitric oxide (NO) production in favour of superoxide. ${ }^{83}$ Vascular inflammation is further promoted by expression of endothelial cell adhesion molecules, which is induced by adipokines such as visfatin, ${ }^{84}$ and adipose tissue-derived pro-inflammatory cytokines such as IL-1 $\beta$ and tumour necrosis factor (TNF). ${ }^{48}$ Some adipokines, such as leptin, have multiple, and often contradicting effects on different cell types and in different disease substrates. ${ }^{85}$ For example, whereas endothelial leptin signalling is considered to be protective against neotintima formation, obesity-induced leptin resistance can reverse this balance towards an atherogenic phenotype. ${ }^{86}$ Central signalling pathways, such as the nuclear factor (NF)-KB pathway, have a critical role in orchestrating this range of proatherogenic effects and are either inhibited (for example, by adiponectin, and fibroblast growth factor 21) or activated (for example, by leptin, visfatin, and RBP4) by specific adipokines. $48,57,84$

MicroRNAs - small RNAs involved in post-transcriptional regulation - are also produced by the adipose tissue, and their profile changes in response to obesity, insulin resistance, ${ }^{87}$ and coronary artery disease (CAD). ${ }^{88}$ MicroRNAs have been shown to orchestrate several processes, ranging from the recruitment of inflammatory cells to the dysfunctional adipose tissue, ${ }^{89}$ to the regulation of insulin sensitivity. ${ }^{90}$ However, adipose tissue-derived microRNAs packed in extracellular vesicles such as exosomes and microparticles are also released into the circulation, enabling the adipose tissue to regulate gene expression in remote tissues. ${ }^{66}$ The spectrum of microRNAs is vast, and numerous microRNAs have been linked to adipose tissue browning, ${ }^{91}$ inflammation, ${ }^{87}$ myocardial fibrosis, atherosclerosis, and VSMC activation. ${ }^{66,91,92}$ Furthermore, VAT-derived exosomes from mice with high 
fat diet-induced obesity have been shown to promote M1 pro-inflammatory polarization of macrophages and to accelerate atherosclerosis in $\mathrm{Apoe}^{-/-}$mice, whereas no such effects were described for SAT-derived or VAT-derived exosomes from wild-type mice, ${ }^{67}$ suggesting depot-specific variations in exosome production. The differential regulation of adipose tissue-derived exosomes and microRNAs in obesity and diabetes mellitus, as well as the proven effects of weight loss and exercise on the levels of specific microRNAs in the adipose tissue, have highlighted microRNAs as potential therapeutic targets in obesity-related CVD. ${ }^{93}$

Gaseous messengers represent another class of mediators of the adipose tissuecardiovascular system interactions. Gaseous messengers include NO, which is produced by adipocyte or macrophage NOS and exerts paracrine anti-inflammatory effects, and adipose tissue-derived $\mathrm{H}_{2} \mathrm{~S}$. Disturbed production of these mediators in obesity has been associated with endothelial dysfunction and with pro-atherogenic effects..$^{68,94,95}$

Local immunological properties of PVAT are increasingly being recognised as critical regulators of PVAT function. Further to the role of macrophage polarization in regulating PVAT function, ${ }^{38}$ experimental evidence suggests that PVAT eosinophils regulate the anticontractile response of PVAT ${ }^{25}$ whereas PVAT-residing B1 cells exert atheroprotective effects through the production of IgM against oxidation-specific epitopes on LDL. ${ }^{24}$ PVAT inflammation is also associated with vascular dysfunction in hypertension, and is mediated by a range of cytokines and chemokines such as CCchemokine ligand 5 (CCL5; also known as RANTES) that mediate T-cell infiltration in the perivascular space, ${ }^{96}$ as well as with complement C5a-mediated decrease in adiponectin production, which promotes hypertensive vascular inflammation. ${ }^{97}$

The importance of sensory innervation of the adipose tissue has also been described. Sensory nerves within PVAT contribute to neurogenic vasorelaxation and crosstalk with adipocytes, leading to leptin-induced relaxation mediated by calcitonin gene-related peptide, a mechanism that is downregulated with reduced oxygenation, such as in obesity-induced adipose tissue dysfunction. ${ }^{98}$ 


\section{Effects on the heart and cardiomyocytes}

The effects of the adipose tissue on the cardiovascular system are not limited to the vascular wall, but important interactions have also been reported with the myocardium (Figure 3 ). ${ }^{99}$ Of all the adipose tissue depots, EAT is most closely associated with myocardial biology, given the absence of an anatomical barrier between the EAT and the myocardium and the vascularization of EAT by the coronary vessels, which allow a paracrine and vasocrine crosstalk between the two organs. EAT provides mechanical, thermogenic, and possibly metabolic support (in the form of free fatty acids) to the adjacent myocardium. ${ }^{13}$ The EAT is further characterised by a distinctive transcriptomic signature, enriched in genes involved in inflammation, thrombosis, and extracellular matrix remodelling. ${ }^{17}$ The close interaction between the EAT and its neighbouring structures might explain further site-specific variations in its transcriptome. For instance, compared with non-pericoronary EAT, pericoronary EAT expresses high levels of BAT-related genes such as UCP1, whereas periatrial EAT is characterised by overexpression of genes involved in cardiac muscle contraction. ${ }^{17}$

Our group has shown that adipose tissue-derived adiponectin exerts anti-oxidant effects on cardiomyocytes through suppression of myocardial NADPH-oxidase activity, by preventing AMPKmediated membrane translocation of RACc1 and $\mathrm{p} 47^{\text {phox }}{ }^{100}$ This action might represent a protective mechanism to prevent deleterious arrhythmogenesis and other effects of myocardial oxidative stress. ${ }^{101}$ Other protective effects include the autocrine and paracrine effects of WNT1-induciblesignalling pathway protein 2 on promoting insulin sensitivity and heart hyperplasia. ${ }^{102}$ Conversely, RBP4 reduces the expression of the insulin-dependent glucose transporter 4 (GLUT4) in cardiomyocytes, thereby promoting insulin resistance, and also induces cardiomyocyte hypertrophy by activating Toll-like receptor 4-dependent inflammatory pathways, suggesting a vicious circle between insulin resistance and heart failure. ${ }^{103}$ Cardiomyocyte metabolism is also affected by activin A, which impairs insulin action via upregulation of miR-143, ${ }^{104}$ whereas chemerin induces cardiomyocyte apoptosis through reduced AKT phosphorylation and increased cleavage of caspase 9. ${ }^{105}$ Studies in rat cardiomyocytes incubated with conditioned media from EAT isolated from patients 
with diabetes mellitus have shown that products secreted by the EAT impair cardiomyocyte contractile function and mitochondrial $\beta$-oxidation via activation of the cardiac-specific RAAS system and induction of miR-208a. ${ }^{106}$ Certain adipokines, such as osteopontin and leptin (known as "adipofibrokines") also promote cardiac fibrosis, possibly through modulation of fibroblast senescence ${ }^{107}$ or through mineralocorticoid receptor-dependent and oxidative stress-dependent pathways, which regulate the production of end effectors (such as transforming growth factor- $\beta$; TGF$\beta)$ responsible for the synthesis of extracellular matrix in cardiac fibroblasts. ${ }^{108}$ EAT might also contribute to atrial fibrillation pathogenesis through the release of activin $A$, which promotes atrial fibrosis and remodelling. ${ }^{109,110}$ In addition, increased EAT aromatase activity might be involved in arrhythmogenesis through local steroid conversion and increased $17 \beta$-estradiol levels. ${ }^{111}$

Overall, phenotypic, proteomic, and structural changes in EAT are evident in several cardiac conditions, including atrial fibrillation, which is associated with fibrotic changes in subepicardial adipose tissue. ${ }^{112}$ Heart failure and cardiomyopathy are also associated with extensive remodelling of the EAT extracellular matrix, ${ }^{113}$ upregulation of EAT lipolysis leading to local release of potentially harmful lipolytic intermediates, ${ }^{114}$ and loss of BAT features, which are believed to exert protective effects against the development of heart failure. ${ }^{115}$

\section{Bidirectional crosstalk}

Changes in cardiovascular biology can affect adipose tissue biology in a bidirectional loop, with important implications in CVD pathogenesis and, as discussed below, diagnosis. Early studies demonstrated the upregulation of pro-inflammatory adipocytokines and downregulation of adiponectin in PVAT following vascular injury in mice, effects that were mediated by upregulation of $\mathrm{TNF}^{116}$. Our group later demonstrated that in the presence of increased vascular oxidative stress, the release of lipid peroxidation products (such as 4-hydroxynonenal) into the surrounding PVAT activates peroxisome proliferator-activated receptor- $\gamma$ (PPAR $\gamma$ ) signalling, leading to increased adiponectin biosynthesis, which then exerts antioxidant effects on the vascular wall in a protective, feedback 
mechanism. ${ }^{56,73,117}$ Our group also described that in the presence of coronary inflammation and atherosclerotic disease, the release of pro-inflammatory mediators from the vascular wall into the surrounding PVAT results in impaired adipocyte differentiation and intracellular lipid formation, with important implications in cardiovascular diagnostics.$^{118}$ This interplay can be mediated by various molecules, including endothelium-derived microparticles containing miR-19b, which have been shown to induce PVAT inflammation and promote atherogenesis in Apo $e^{-/-}$mice. ${ }^{119}$

Such paracrine interactions are not confined to the vascular wall. Our group has uncovered similar links between the myocardium and EAT. Similarly to the vessels, myocardial-derived oxidation products lead to PPAR $y$-mediated upregulation of adiponectin biosynthesis in the adjacent EAT, which then exerts antioxidant effects on the cardiomyocytes. ${ }^{100}$ In addition to the EAT, we have also identified communication links between the myocardium and remote adipose tissue depots, establishing that among patients with advanced atherosclerosis, circulating brain natriuretic peptide (BNP) levels, rather than systemic inflammation, are the principal driver of circulating adiponectin levels. ${ }^{23}$ The existence of inside-to-outside signalling pathways is further supported by data from other studies. In mice, natriuretic peptides stimulate adipose tissue browning, ${ }^{119}$ improving energy expenditure and insulin sensitivity. ${ }^{120}$ By contrast, atrial myocyte-secreted atrial natriuretic peptide (ANP) is a major adipogenic factor mediated by natriuretic peptide receptor A (NPRA) pathway activation, contributing to a potentially pro-arrhythmogenic crosstalk between EAT expansion and mechanical function of the atrial myocardium. ${ }^{121}$ Finally, similar to coronary inflammation, ${ }^{118}$ in myocardial disease states such as systolic heart failure, the local release of inflammatory mediators (such as IL-6 and TNF) can trigger EAT lipolysis, thus providing a possible mechanistic explanation for the observed negative association between EAT volume and left ventricular ejection fraction in these patients. ${ }^{60}$

\section{Effects of ectopic fat deposition}


Further to the traditional adipose tissue depots, ectopic fat deposition either in the liver (non-alcoholic fatty liver disease; NAFLD), the myocardium, or in skeletal muscle is increasingly recognised as a cardiometabolic risk factor, and has been linked to increased prevalence of coronary atherosclerosis and higher incidence of adverse cardiovascular events. ${ }^{122,123}$ Indeed, clinical studies have established hepatic and cardiac steatosis as hallmarks of type 2 diabetes mellitus, independently of BMI, and have further linked ectopic fat expansion in these depots to marked abnormalities in cardiac structure and energetics. ${ }^{124}$ Intrahepatic triglyceride content (IHTG) has been proposed as a better marker of insulin resistance and dysregulated fatty acid transport than VAT. ${ }^{125}$ Indeed, VAT volume and the presence of insulin resistance are not associated in individuals matched for IHTG, suggesting that the close association between visceral obesity and metabolic disease is mediated by a link between VAT expansion and IHTG. ${ }^{125}$ Although the exact pathophysiological mechanisms linking IHTG and NAFLD with CVD are unclear, an imbalanced adipokine profile in obesity and metabolic disease (characterised by decreased adiponectin levels and increased leptin, visfatin, chemerin, and resistin levels) seems to contribute to metabolic inflammation, driving ectopic intrahepatic fat accumulation. ${ }^{126}$ Intrahepatic fat is in turn associated with hepatic and/or peripheral insulin resistance, dyslipidaemia, and secretion of several pro-inflammatory and pro-atherogenic factors, and is further linked to early alterations in cardiac substrate metabolism, as well as functional, structural, and proarrhythmic cardiac changes, ${ }^{123}$ even though the causality of the observed associations is not yet established. In addition to intrahepatic fat, a community-based study of 3,051 participants identified intramuscular adipose tissue expansion as an independent risk factor for the presence of coronary atherosclerosis, further highlighting the importance of ectopic fat deposition in CVD. ${ }^{127}$

\section{Effects on cardiovascular outcomes}

The association between the adipose tissue and CVD is supported by numerous clinical studies. Results from a large-scale, Mendelian randomization analysis revealed a positive, causal association between higher levels of both general and central adiposity with CAD, stroke, and type 2 diabetes mellitus, as 
well as associations with left ventricular hypertrophy, circulating IL-6 levels, and dyslipidaemia. ${ }^{128} \mathrm{~A}$ series of studies, including evidence from the landmark Dallas and Framingham Heart Studies, have demonstrated a positive association between visceral adiposity, but not total or subcutaneous adiposity, with incident hypertension, ${ }^{129}$ as well as an incremental value for VAT beyond BMI for the prediction of incident CVD. ${ }^{6,130}$ Conversely, EAT volume is independently and positively associated with coronary stenosis, myocardial ischaemia, major adverse cardiac events, ${ }^{131}$ incidence of atrial fibrillation, ${ }^{132}$ and even clinical presentation and outcomes in patients with pericarditis. ${ }^{133}$ Beyond volumetric fat assessment, adipose tissue quality and, more specifically, supraclavicular BAT activity have been shown to be inversely associated with arterial inflammation and the risk of future cardiovascular events in humans. ${ }^{134}$ Other studies have explored the clinical importance of the circulating adipokine profile. Two meta-analyses of prospective studies have revealed a positive association between circulating adiponectin levels with coronary heart disease recurrence and with all-cause and cardiovascular mortality among patients with established CVD. ${ }^{55}$ Other studies have linked high resistin levels to increased risk of all-cause and cardiovascular death, ${ }^{53}$ high visfatin levels to increased risk of adverse cardiac events among patients with myocardial infarction, ${ }^{135}$ and high RBP4 levels to a higher incidence of CVD. ${ }^{49}$

\section{Noninvasive phenotyping of adipose tissue}

Adipose tissue phenotyping for cardiometabolic risk stratification in the clinical setting can be performed in an inexpensive way through simple anthropometric measurements. For instance, in addition to the calculation of BMI, simultaneous interpretation of waist circumference and fasting plasma triglyceride concentration (a combination referred to as "hypertriglyceridaemic waist") has shown good diagnostic accuracy for the identification of men with the so-called atherogenic metabolic triad (elevated insulin, apolipoprotein B, and small-dense LDL levels in plasma), who are at high risk of CAD. ${ }^{136}$ However, the inherent limitations of traditional anthropometric indices in explaining the association between obesity and CVD have led to the development of several imaging modalities that 
can extract both quantitative and qualitative features of adipose tissue distribution and composition (Figure 4). Each imaging technique has different strengths and limitations, as summarized in Table 2. Dual energy X-ray absorptiometry (DEXA). DEXA is a modality commonly used to measure body fat mass, and relies on the analysis of the body absorption of two X-ray beams at different energy levels. Despite being a fairly easy, widely available modality, DEXA cannot easily characterize distinct adipose tissue depots and can have practical limitations when imaging morbidly obese individuals. ${ }^{137}$

Ultrasound and transthoracic echocardiography. Ultrasound can be used to assess subcutaneous (deep versus superficial SAT) and gluteal adipose tissue thickness ${ }^{8}$. Transthoracic echocardiography can provide an easy, ${ }^{138}$ although operator-dependent, assessment of EAT thickness.

CT imaging and MRI. Use of CT imaging enables to quantify accurately adipose tissue volumetric characteristics in different depots by applying standardized CT attenuation thresholds and segmentation algorithms, at the cost of radiation exposure. ${ }^{6}$ By contrast, use of MRI avoids radiation exposure at the cost of longer acquisition times and reduced spatial resolution. ${ }^{139}$ In addition, when combined with nuclear MR spectroscopy, MRI can allow noninvasive detection of adipose tissue browning. ${ }^{140}$

[PET-CT and PET-MRI. Qualitative information on adipose tissue composition can be extracted by using ${ }^{18}$ Fluorodeoxyglucose (FDG) PET-CT or PET-MRI, where FDG uptake reflects the metabolic and inflammatory activity of adipose tissue. ${ }^{141-143}$ High ${ }^{18}$ F-FDG uptake by coronary PVAT has been linked to drug-eluting stent-induced coronary hyperconstricting responses in pigs in vivo, ${ }^{142}$ and with vasospastic angina ${ }^{143}$ and the extent of coronary atherosclerosis ${ }^{141}$ in humans.

[Fat Attenuation Index. In a study published in 2017, our group showed that routine CT imaging can provide sufficient information to identify the composition and biology of the adipose tissue by means of the standardized attenuation of the CT signal for the adipose tissue (adipose tissue CT attenuation). ${ }^{118}$ To this end, we developed a novel CT-derived metric of adipose tissue attenuation (followed by appropriate post-processing adjustments), namely the Fat Attenuation Index (FAl), that reflects the degree of adipocyte differentiation and lipid accumulation in a given adipose tissue 
depot. ${ }^{118}$ The FAI of remote depots such as VAT and SAT is inversely associated with insulin resistance, independently of adipose tissue volume, possibly owing to the negative association of the FAI with adipocyte size and hypertrophy, which are linked to adipose tissue dysfunction and metabolic disease. ${ }^{118,144}$ However, we did not find an association between perivascular FAI (FAlpvat) and insulin resistance, suggesting that FAl pvat is independent of systemic factors ${ }^{118}$ and is mediated by local, paracrine interactions. ${ }^{56,73}$ Indeed, we had previously observed that the release of pro-inflammatory mediators from the diseased coronary vessel blocks adipocyte differentiation in the adjacent PVAT, creating a gradient of increasing adipocyte size and lipid accumulation from the PVAT adjacent to the diseased vascular wall to PVAT in distal regions. By developing a new technology that allowed a 3D analysis of FAI changes around the coronary vessels on coronary CT angiograms, we demonstrated that FAlPVAT was strongly associated with the presence of CAD, could reliably separate unstable from stable lesions in patients with acute coronary syndromes, and exhibited dynamic changes in response to fluctuations in coronary inflammation, suggesting a novel, noninvasive, adipose tissue-based biomarker of vascular inflammation. ${ }^{118}$

Other techniques. New experimental imaging techniques provide an insight into adipose tissue structural changes, including browning. Diffuse optical spectroscopy techniques can detect changes in SAT structure following weight loss in humans, correlating with changes in adipocyte size, haemoglobin levels, and water content, ${ }^{145}$ and can also reliably assess adipose tissue browning and the transitioning to a beige phenotype in adipose tissue explants. ${ }^{146}$ In vivo xenon-enhanced CT has been shown to detect BAT through accumulation of the lipophilic gas xenon in BAT following stimulation of thermogenesis. ${ }^{147}$ Finally, advanced videomicroscopy techniques can now assess the vasomotor function of small VAT arterioles in obese individuals, and can be used to evaluate the response of pharmacological interventions targeting the adipose tissue. ${ }^{148}$

\section{Targeting the adipose tissue in CVD}


Several experimental therapeutic approaches targeting the adipose tissue have shown cardiovascular benefit in animal models or early preclinical studies. In most cases, the clinical translation of adipose tissue-targeting approaches into safe, inexpensive, and effective interventions remains a lengthy and often unsuccessful process. Nevertheless, simple lifestyle interventions and commonly used medications can improve adipose tissue function with a substantial cardiovascular benefit.

\section{Antihyperglycaemic medications}

Ever since the ORIGIN trial ${ }^{149}$ showed that providing basal insulin to normalize fasting plasma glucose levels did not reduce cardiovascular events in patients with cardiovascular risk factors plus dysglycaemia, several trials on different classes of antihyperglycaemic medications, including glucagon-like peptide (GLP1) agonists (such as liraglutide), ${ }^{150}$ dipeptidyl peptidase 4 (DPP4) inhibitors (sitagliptin) ${ }^{151}$, and sodium-glucose transporter 2 (SGLT2inhibitors (such as empagliflozin) ${ }^{152}$, have demonstrated significant cardiovascular benefits among patients with diabetes. Therefore, it has been hypothesized that the cardioprotective effects of these interventions are independent of their antihyperglycaemic effects.

GLP1 agonists and DPP4 inhibitors (gliptins). GLP1 is an incretin that is mainly produced by the intestinal epithelial endocrine L-cells in response to meal intake, and is responsible for insulin secretion, glucagon inhibition, and decreased gastrointestinal motility in the post-prandial setting. ${ }^{153}$ GLP1 is inactivated by DPP4, an enzyme that was found to be expressed in the adipose tissue. ${ }^{154,155} \mathrm{As}$ such, GLP1 agonists and DPP4 inhibitors are now increasingly being used in the management of type 2 diabetes mellitus, and have been shown to improve cardiovascular outcomes in clinical trials. ${ }^{150,151}$ Evidence suggest that the adipose tissue might have an important role in these observed effects. DPP4 is an adipokine that exerts autocrine and paracrine effects on the adipose tissue and correlates with adipocyte size and several metabolic syndrome parameters ${ }^{154}$. Studies in animal models have shown that DPP4 inhibition prevents obesity-associated inflammation and insulin resistance by regulating 
M1/M2 macrophage polarization in VAT, ${ }^{155}$ and blocks adipose tissue fibrosis possibly through neuropeptide $\mathrm{Y}$ activation. ${ }^{156}$ In patients with type 2 diabetes, treatment with DPP4 antgonists has been shown to reduce hepatic fat content, and in women, possibly also reduces myocardial fat content ${ }^{159}$. Direct GLP1 agonism in cultured adipocytes induces adiponectin expression through the protein kinase A pathway, while inhibiting the expression of pro-inflammatory adipokines ${ }^{157}$, and has been shown to promote WAT browning in mice through a sirtuin 1-dependent mechanism ${ }^{158}$. In patients with type 2 diabetes, reatment with the GLP1 agonist liraglutide causes a rapid, significant reduction in EAT volume ${ }^{153}$.

SGLT2 inhibitors (gliflozins). SGLT2 is a sodium-glucose transporter responsible for renal glucose reabsorption. While pharmacological SGLT2 inhibition is targeted at decreasing blood glucose levels, SGLT2 inhibition has also been shown to exert direct adipose tissue effects. ${ }^{152}$ These effects include reduced expression of pro-inflammatory chemokines, increased insulin sensitivity, and adipocyte differentiation in EAT explants, ${ }^{160}$ as well as a marked reduction in the amount of EAT in humans, ${ }^{161}$ which might explain the cardioprotective profile of SGLT2 inhibitors described in clinical trials. ${ }^{152}$ This cardioprotective effect might be mediated by a negative caloric balance caused by the loss of glucose in urine, as well as by the higher levels of visceral adiposity found in individuals with type 2 diabetes compared with individuals with normoglycaemia, independently from total adiposity levels. ${ }^{162}$

PPARY agonists. The clinical benefit and safety profile of targeting the PPARY axis remains contentious, ever since a meta-analysis showed an increased risk of CVD in patients treated with rosilitazone (a member of the thiazolidinediones group). ${ }^{163}$ Treatment with pioglitazone in animal models has been shown to promote atherosclerotic plaque stability, affecting the outside-to-inside effects of PVAT through downregulation of PVAT inflammation and inflammatory adipokine expression profile, ${ }^{164}$. Saroglitazar, another PPARY agonist, prevents obesity-induced adipose tissue dysfunction in mice by limiting diet-induced adipocyte hypertrophy, cell damage, and extracellular matrix deposition. ${ }^{165}$ As 
PPAR $\gamma$ is a critical regulator of adipogenesis, PPAR- $\gamma$ agonists might also exert beneficial effects by promoting adipocyte differentiation, predominantly in the subcutaneous depot, ${ }^{166}$ thus creating a "metabolic sink" and protecting against VAT expansion and ectopic fat deposition.

\section{Other cardiovascular medications}

The adipose tissue is a target of several other commonly used medications. The adipose tissue produces both angiotensinogen and angiotensin II, therefore contributing to local and possibly systemic activation of the RAAS. ${ }^{167}$ The adipocytes also express both type 1 and type 2 angiotensin II receptors, which are involved in autocrine, paracrine, and endocrine signalling. ${ }^{167}$ Activation of the type 1 angiotensin II receptor in $\mathrm{Apoe}^{-/-}$mice promotes M1 macrophage polarization and osteopontin expression in PVAT and increases gelatinolytic activity in the aorta, contributing to aortic aneurysm formation ${ }^{168}$. Type 2 angiotensin II receptor activation in cultures of mouse primary white adipocytes promotes adipose browning and BAT adipogenesis through PPARy activation. ${ }^{167}$ Mineralocorticoidreceptor activation is involved in adipocyte development, but increased activation in disease states promotes oxidative stress, inflammatory adipokine expression, and dysregulates adipocyte autophagy. ${ }^{169}$ Therefore, pharmacological modification of the RAAS in the adipose tissue might mediate part of the beneficial effects of angiotensin-converting enzyme inhibitors, angiotensin IIreceptor blockers, aldosterone-receptor antagonists (such as spironolactone), or novel therapeutic $\operatorname{agents}^{170}$.

Other medications might act in a synergistic way with BAT activation to promote the beneficial effects of the medication. For example, atorvastatin accelerates the hepatic uptake of lipoprotein remnants generated by BAT activation, further promoting the lipid-lowering and anti-atherogenic effects of atorvastatin. ${ }^{171}$ Methotrexate decreases the expression of pro-inflammatory cytokines in PVAT and promotes adiponectin expression, possibly through increased AMPK phosphorylation, therefore restoring eNOS phosphorylation and endothelial function. ${ }^{128}$ Given the demonstrated cardiovascular benefits of anti-inflammatory biological agents such as canakinumab in patients with 
established CVD, ${ }^{172}$ pharmacological modulation of adipose tissue inflammation should be further explored in the future.

\section{Exercise and diet}

The effects of obesity on cardiovascular parameters, such as the association with concentric left ventricular remodelling, are reversible with weight loss. ${ }^{173}$ Caloric restriction improves vascular insulin sensitivity and attenuates the age-related increase in pro-inflammatory cytokine production in PVAT in rats, ${ }^{174}$ whereas isocaloric intermittent fasting in mice prevents obesity-related metabolic dysfunction through increased adipose tissue thermogenesis and fasting-mediated periodic upregulation of VEGF in WAT, which is linked with M2 macrophage polarization and WAT browning. ${ }^{175}$ Aerobic exercise in male rats decreases the levels of circulating insulin, leptin, and TNF, reduces the expression of the inducible isoform of NOS in PVAT, and restores the anticontractile vascular effect of PVAT compared with sedentary rats. ${ }^{176}$ Of note, clinical studies in adult men suggest that exerciseinduced weight loss is more effective in improving circulating adipokine profiles and insulin resistance than dieting alone. ${ }^{177}$ The beneficial effects of exercise without caloric restriction on fat reduction, insulin resistance, ${ }^{178}$ and improvement in circulating adipokine profile, ${ }^{177}$ have long been documented in randomized, controlled, clinical trials. ${ }^{178}$ High-intensity, interval training has been shown to be particularly effective in reducing total adipose tissue and VAT mass in adults and in increasing cardiorespiratory fitness in obese children ${ }^{179,180}$; nevertheless, meaningful weight loss can also be achieved by simple activities such as active commuting. ${ }^{181}$

\section{Bariatric surgery}

Bariatric surgery, most commonly Roux-en-Y gastric bypass (RYGB), is usually reserved as a last resort to treat morbid obesity and obesity-related metabolic complications, and has been found to be superior to intensive medical therapy in resolving hyperglycaemia among patients with type 2 diabetes mellitus, ${ }^{182}$ with long-lasting benefits for weight loss and prevention of metabolic disease. ${ }^{183}$ 
The beneficial effects of bariatric surgery can be attributed both to weight reduction per se, as well as to increased production of postprandial GLP1 and GLP1-stimulated insulin secretion. ${ }^{184}$ A range of beneficial changes, including reduced macrophage and T cell infiltration into the adipose tissue, ${ }^{185}$ increased circulating and adipose tissue-secreted adiponectin levels, as well as decreased lipolysis and adipocyte cell size, might also account for the beneficial effects of bariatric surgery. ${ }^{186}$

\section{Experimental interventions}

BAT activation and adipose tissue browning. Less than one half of BAT volume in humans is stimulated by cold exposure, while men with obesity have significantly lower BAT activation than men with normal weight, suggesting a promising therapeutic potential for adipose tissue browning in humans. ${ }^{18}$ Whereas in rodents, WAT browning has been reported in response to exercise ${ }^{187}$ or intermitted fasting, ${ }^{45}$ in humans, exercise alone or caloric restriction-induced weight loss do not promote BAT activation or WAT browning. ${ }^{188-190}$ Pharmacological modulation of BAT activity and WAT browning in animal models can be achieved by targeting VEGF receptor $1^{191}$ and by administration of retinoic acid $^{192}$ or tetrahydrobiopterin, ${ }^{193}$ whereas in humans, thyroid hormone stimulation ${ }^{194}$ and $\beta 3$ adrenergic agonists have been reported to stimulate BAT activity. ${ }^{195}$ Of note, nanoparticles targeted to the adipose tissue might improve the selectivity and therefore safety of therapeutic interventions, such as delivery of microRNAs. ${ }^{196}$

Adipose-derived stem cells. Adipose-derived stem cells have emerged as crucial targets in CVD given their cardioprotective and regenerative potential. For instance, exosomes from adipose-derived stem cells have been shown to protect cardiomyocytes against ischaemia-reperfusion injury. ${ }^{197}$ Advances in stem cell engineering have also enabled the use of adipose-derived stem cells for myocardial tissue repair, with promising findings from animal studies. Compared with saline, infusion of adipose-derived stem cells into the left ventricle in rat models of coronary artery ligation resulted in significantly improved left ventricular systolic function at 12 weeks. ${ }^{198}$ Moreover, in a porcine model of myocardial 
infarction intracoronary infusion of autologous adipose-derived stem cells promoted cardioprotective and reparative mechanisms and improved myocardial perfusion, despite showing no effects on the systolic or diastolic ventricular function. ${ }^{199}$

\section{Conclusions}

The adipose tissue is a dynamic organ, involved in a range of pleiotropic interactions with the cardiovascular system. As such, the adipose tissue is increasingly being recognised both as a crucial regulator of cardiovascular health and as a driver of CVD pathogenesis. In the modern era of precision medicine, our expanding knowledge on adipose tissue biology might enable us to overcome the limitations of the traditional anthropometric indices of obesity and to move closer to an individualised understanding of the adipose tissue and its contribution to cardiometabolic health. Novel, noninvasive techniques of adipose tissue phenotyping have the potential to transform cardiovascular risk stratification, whereas established and experimental pharmacological and other interventions can modify an individual's adipose tissue profile with beneficial effects in both primary and secondary CVD prevention. Importantly, a substantial body of evidence suggests that simple lifestyle interventions, including exercise and diet, are effective in promoting a healthy adipose tissue phenotype and even in reversing adipose tissue dysfunction and related adverse cardiometabolic effects. The adipose tissue, long believed to be a foe of the cardiovascular system, could therefore be turned into a powerful ally in our fight against CVD, by providing a range of prognostic biomarkers and therapeutic targets.

\section{REFERENCES}

1 Benjamin, E. J. et al. Heart Disease and Stroke Statistics-2017 Update: A Report From the American Heart Association. Circulation 135, e146-e603 (2017).

2 Rimm, E. B. et al. Body size and fat distribution as predictors of coronary heart disease among middle-aged and older US men. Am J Epidemiol 141, 1117-1127 (1995).

3 Hartz, A. J., Rupley, D. C., Jr., Kalkhoff, R. D. \& Rimm, A. A. Relationship of obesity to diabetes: influence of obesity level and body fat distribution. Prev Med 12, 351-357 (1983). 
Aune, D. et al. BMI and all cause mortality: systematic review and non-linear dose-response meta-analysis of 230 cohort studies with 3.74 million deaths among 30.3 million participants. BMJ 353, i2156 (2016).

Powell-Wiley, T. M. et al. Impact of Body Mass Index on Heart Failure by Race/Ethnicity From Get With The Guidelines-Heart Failure (GWTG-HF) Registry. JACC Heart Fail (2018). Britton, K. A. et al. Body fat distribution, incident cardiovascular disease, cancer, and all-cause mortality. J Am Coll Cardiol 62, 921-925 (2013).

Silva, K. R. et al. Characterization of stromal vascular fraction and adipose stem cells from subcutaneous, preperitoneal and visceral morbidly obese human adipose tissue depots. PLoS One 12, e0174115 (2017).

Marinou, K. et al. Structural and functional properties of deep abdominal subcutaneous adipose tissue explain its association with insulin resistance and cardiovascular risk in men. Diabetes Care 37, 821-829 (2014).

Bowman, K. et al. Central adiposity and the overweight risk paradox in aging: follow-up of 130,473 UK Biobank participants. Am J Clin Nutr 106, 130-135 (2017).

10 Flier, J. S., Cook, K. S., Usher, P. \& Spiegelman, B. M. Severely impaired adipsin expression in genetic and acquired obesity. Science 237, 405-408 (1987).

11 Akoumianakis, I. \& Antoniades, C. The interplay between adipose tissue and the cardiovascular system: is fat always bad? Cardiovasc Res 113, 999-1008 (2017).

12 Wajchenberg, B. L. Subcutaneous and visceral adipose tissue: their relation to the metabolic syndrome. Endocr Rev 21, 697-738 (2000).

13 lacobellis, G. Local and systemic effects of the multifaceted epicardial adipose tissue depot. Nat Rev Endocrinol 11, 363-371 (2015).

14 Vohl, M. C. et al. A survey of genes differentially expressed in subcutaneous and visceral adipose tissue in men. Obes Res 12, 1217-1222 (2004).

15 Salgado-Somoza, A., Teijeira-Fernandez, E., Fernandez, A. L., Gonzalez-Juanatey, J. R. \& Eiras, $\mathrm{S}$. Proteomic analysis of epicardial and subcutaneous adipose tissue reveals differences in proteins involved in oxidative stress. Am J Physiol Heart Circ Physiol 299, H202-209 (2010).

16 Passaro, A. et al. Gene expression regional differences in human subcutaneous adipose tissue. BMC Genomics 18, 202 (2017).

17 Gaborit, B. et al. Human epicardial adipose tissue has a specific transcriptomic signature depending on its anatomical peri-atrial, peri-ventricular, or peri-coronary location. Cardiovasc Res 108, 62-73 (2015).

18 Leitner, B. P. et al. Mapping of human brown adipose tissue in lean and obese young men. Proc Natl Acad Sci U S A 114, 8649-8654 (2017).

19 Harms, M. \& Seale, P. Brown and beige fat: development, function and therapeutic potential. Nat Med 19, 1252-1263 (2013).

20 Villarroya, F., Cereijo, R., Villarroya, J. \& Giralt, M. Brown adipose tissue as a secretory organ. Nature Reviews Endocrinology 13, 26-35 (2017).

21 Stanford, K. I. et al. Brown adipose tissue regulates glucose homeostasis and insulin sensitivity. J Clin Invest 123, 215-223 (2013).

22 Gronthos, S. et al. Surface protein characterization of human adipose tissue-derived stromal cells. J Cell Physiol 189, 54-63 (2001).

23 Antonopoulos, A. S. et al. Reciprocal effects of systemic inflammation and brain natriuretic peptide on adiponectin biosynthesis in adipose tissue of patients with ischemic heart disease. Arterioscler Thromb Vasc Biol 34, 2151-2159 (2014).

24 Srikakulapu, P. et al. Perivascular Adipose Tissue Harbors Atheroprotective IgM-Producing B Cells. Front Physiol 8, 719 (2017).

25 Withers, S. B. et al. Eosinophils are key regulators of perivascular adipose tissue and vascular functionality. Sci Rep 7, 44571 (2017). 
26 Zuk, P. A. et al. Human adipose tissue is a source of multipotent stem cells. Mol Biol Cell 13, 4279-4295 (2002).

27 Tilg, H. \& Moschen, A. R. Adipocytokines: mediators linking adipose tissue, inflammation and immunity. Nat Rev Immunol 6, 772-783 (2006).

28 Chusyd, D. E., Wang, D., Huffman, D. M. \& Nagy, T. R. Relationships between Rodent White Adipose Fat Pads and Human White Adipose Fat Depots. Front Nutr 3, 10 (2016).

29 Fuster, J. J., Ouchi, N., Gokce, N. \& Walsh, K. Obesity-Induced Changes in Adipose Tissue Microenvironment and Their Impact on Cardiovascular Disease. Circ Res 118, 1786-1807 (2016).

30 Krotkiewski, M., Bjorntorp, P., Sjostrom, L. \& Smith, U. Impact of obesity on metabolism in men and women. Importance of regional adipose tissue distribution. J Clin Invest 72, 11501162 (1983).

31 Salans, L. B., Knittle, J. L. \& Hirsch, J. The role of adipose cell size and adipose tissue insulin sensitivity in the carbohydrate intolerance of human obesity. J Clin Invest 47, 153-165 (1968).

32 Rutkowski, J. M., Stern, J. H. \& Scherer, P. E. The cell biology of fat expansion. J Cell Biol 208, 501-512 (2015).

33 Kursawe, R. et al. Cellularity and adipogenic profile of the abdominal subcutaneous adipose tissue from obese adolescents: association with insulin resistance and hepatic steatosis. Diabetes 59, 2288-2296 (2010).

34 Guzik, T. J., Skiba, D. S., Touyz, R. M. \& Harrison, D. G. The role of infiltrating immune cells in dysfunctional adipose tissue. Cardiovasc Res 113, 1009-1023 (2017).

35 Weisberg, S. P. et al. Obesity is associated with macrophage accumulation in adipose tissue. J Clin Invest 112, 1796-1808 (2003).

36 Cildir, G., Akincilar, S. C. \& Tergaonkar, V. Chronic adipose tissue inflammation: all immune cells on the stage. Trends Mol Med 19, 487-500 (2013).

37 Caer, C. et al. Immune cell-derived cytokines contribute to obesity-related inflammation, fibrogenesis and metabolic deregulation in human adipose tissue. Sci Rep 7, 3000 (2017).

38 Lumeng, C. N., Bodzin, J. L. \& Saltiel, A. R. Obesity induces a phenotypic switch in adipose tissue macrophage polarization. J Clin Invest 117, 175-184 (2007).

39 Fujisaka, S. et al. Regulatory mechanisms for adipose tissue M1 and M2 macrophages in dietinduced obese mice. Diabetes 58, 2574-2582 (2009).

40 Onogi, Y. et al. PDGFRbeta Regulates Adipose Tissue Expansion and Glucose Metabolism via Vascular Remodeling in Diet-Induced Obesity. Diabetes 66, 1008-1021 (2017).

41 Pasarica, M. et al. Reduced adipose tissue oxygenation in human obesity: evidence for rarefaction, macrophage chemotaxis, and inflammation without an angiogenic response. Diabetes 58, 718-725 (2009).

42 Chadderdon, S. M. et al. Proinflammatory endothelial activation detected by molecular imaging in obese nonhuman primates coincides with onset of insulin resistance and progressively increases with duration of insulin resistance. Circulation 129, 471-478 (2014).

43 Halberg, N. et al. Hypoxia-inducible factor 1alpha induces fibrosis and insulin resistance in white adipose tissue. Mol Cell Biol 29, 4467-4483 (2009).

44 Escobedo, N. et al. Restoration of lymphatic function rescues obesity in Prox1haploinsufficient mice. JCI Insight 1 (2016).

$45 \mathrm{Li}$, G. et al. Intermittent Fasting Promotes White Adipose Browning and Decreases Obesity by Shaping the Gut Microbiota. Cell Metab 26, 672-685 e674 (2017).

46 Franssens, B. T., Hoogduin, H., Leiner, T., van der Graaf, Y. \& Visseren, F. L. J. Relation between brown adipose tissue and measures of obesity and metabolic dysfunction in patients with cardiovascular disease. J Magn Reson Imaging 46, 497-504 (2017).

47 Chechi, K. et al. Functional characterization of the Ucp1-associated oxidative phenotype of human epicardial adipose tissue. Sci Rep 7, 15566 (2017). 

Role of Adipose Tissue. Antioxid Redox Signal (2017).

49 Sun, Q. et al. Plasma Retinol-Binding Protein 4 (RBP4) Levels and Risk of Coronary Heart Disease A Prospective Analysis Among Women in the Nurses' Health Study. Circulation 127, 1938-+ (2013).

50 Jacques, C. et al. Proinflammatory Actions of Visfatin/Nicotinamide Phosphoribosyltransferase (Nampt) Involve Regulation of Insulin Signaling Pathway and Nampt Enzymatic Activity. Journal of Biological Chemistry 287, 15100-15108 (2012).

51 Weng, C. et al. Effects of chemerin/CMKLR1 in obesity-induced hypertension and potential mechanism. Am J Transl Res 9, 3096-3104 (2017).

52 Feng, R. et al. Higher vaspin levels in subjects with obesity and type 2 diabetes mellitus: a meta-analysis. Diabetes Res Clin Pract 106, 88-94 (2014).

53 Fontana, A. et al. Association between Resistin Levels and All-Cause and Cardiovascular Mortality: A New Study and a Systematic Review and Meta-Analysis. Plos One 10 (2015).

54 Narumi, T. et al. Impact of serum omentin-1 levels on cardiac prognosis in patients with heart failure. European Heart Journal 35, 221-222 (2014).

55 Wu, Z. J., Cheng, Y. J., Gu, W. J. \& Aung, L. H. Adiponectin is associated with increased mortality in patients with already established cardiovascular disease: a systematic review and metaanalysis. Metabolism 63, 1157-1166 (2014).

56 Margaritis, M. et al. Interactions between vascular wall and perivascular adipose tissue reveal novel roles for adiponectin in the regulation of endothelial nitric oxide synthase function in human vessels. Circulation 127, 2209-2221 (2013).

57 Taube, A., Schlich, R., Sell, H., Eckardt, K. \& Eckel, J. Inflammation and metabolic dysfunction: links to cardiovascular diseases. Am J Physiol Heart Circ Physiol 302, H2148-2165 (2012).

58 Antonopoulos, A. S., Oikonomou, E. K., Antoniades, C. \& Tousoulis, D. From the BMI paradox to the obesity paradox: the obesity-mortality association in coronary heart disease. Obes Rev 17, 989-1000 (2016).

59 Uretsky, S. et al. Obesity paradox in patients with hypertension and coronary artery disease. Am J Med 120, 863-870 (2007).

60 Khawaja, T. et al. Epicardial fat volume in patients with left ventricular systolic dysfunction. Am J Cardiol 108, 397-401 (2011).

61 Lavie, C. J. et al. Impact of cardiorespiratory fitness on the obesity paradox in patients with heart failure. Mayo Clin Proc 88, 251-258 (2013).

62 Lavie, C. J., Osman, A. F., Milani, R. V. \& Mehra, M. R. Body composition and prognosis in chronic systolic heart failure: the obesity paradox. Am J Cardiol 91, 891-894 (2003).

63 Hall, J. E., do Carmo, J. M., da Silva, A. A., Wang, Z. \& Hall, M. E. Obesity-induced hypertension: interaction of neurohumoral and renal mechanisms. Circ Res 116, 991-1006 (2015).

64 Asferg, C. L. et al. Relative atrial natriuretic peptide deficiency and inadequate renin and angiotensin II suppression in obese hypertensive men. Hypertension 62, 147-153 (2013).

65 Vilahur, G., Ben-Aicha, S. \& Badimon, L. New insights into the role of adipose tissue in thrombosis. Cardiovasc Res 113, 1046-1054 (2017).

66 Thomou, T. et al. Adipose-derived circulating miRNAs regulate gene expression in other tissues. Nature 542, 450-455 (2017).

67 Xie, Z. et al. Adipose-Derived Exosomes Exert Proatherogenic Effects by Regulating Macrophage Foam Cell Formation and Polarization. J Am Heart Assoc 7 (2018).

68 King, A. L. et al. Hydrogen sulfide cytoprotective signaling is endothelial nitric oxide synthasenitric oxide dependent. Proc Natl Acad Sci U S A 111, 3182-3187 (2014).

69 Lee, Y. C. et al. Role of perivascular adipose tissue-derived methyl palmitate in vascular tone regulation and pathogenesis of hypertension. Circulation 124, 1160-1171 (2011). 

vascular disease pathogenesis: identifying novel therapeutic targets. Br J Pharmacol 174, 3411-3424 (2017).

71 Yudkin, J. S., Eringa, E. \& Stehouwer, C. D. "Vasocrine" signalling from perivascular fat: a mechanism linking insulin resistance to vascular disease. Lancet 365, 1817-1820 (2005).

72 Chen, H., Montagnani, M., Funahashi, T., Shimomura, I. \& Quon, M. J. Adiponectin stimulates production of nitric oxide in vascular endothelial cells. J Biol Chem 278, 45021-45026 (2003).

73 Antonopoulos, A. S. et al. Adiponectin as a link between type 2 diabetes and vascular NADPH oxidase activity in the human arterial wall: the regulatory role of perivascular adipose tissue. Diabetes 64, 2207-2219 (2015).

74 Chang, L. et al. Bmal1 in Perivascular Adipose Tissue Regulates Resting Phase Blood Pressure Through Transcriptional Regulation of Angiotensinogen. Circulation (2018).

75 Ayala-Lopez, N., Thompson, J. M. \& Watts, S. W. Perivascular Adipose Tissue's Impact on Norepinephrine-Induced Contraction of Mesenteric Resistance Arteries. Front Physiol 8, 37 (2017).

76 Friederich-Persson, M., Nguyen Dinh Cat, A., Persson, P., Montezano, A. C. \& Touyz, R. M. Brown Adipose Tissue Regulates Small Artery Function Through NADPH Oxidase 4-Derived Hydrogen Peroxide and Redox-Sensitive Protein Kinase G-1alpha. Arterioscler Thromb Vasc Biol 37, 455-465 (2017).

77 Margaritis, M. et al. Predictive value of telomere length on outcome following acute myocardial infarction: evidence for contrasting effects of vascular vs. blood oxidative stress. Eur Heart J 38, 3094-3104 (2017).

78 Antoniades, C. et al. Preoperative atorvastatin treatment in CABG patients rapidly improves vein graft redox state by inhibition of Rac1 and NADPH-oxidase activity. Circulation 122, S6673 (2010).

79 Langbein, H. et al. NADPH oxidase 4 protects against development of endothelial dysfunction and atherosclerosis in LDL receptor deficient mice. Eur Heart J 37, 1753-1761 (2016).

80 Antoniades, C. et al. 5-methyltetrahydrofolate rapidly improves endothelial function and decreases superoxide production in human vessels: effects on vascular tetrahydrobiopterin availability and endothelial nitric oxide synthase coupling. Circulation 114, 1193-1201 (2006).

81 Han, F. et al. C1q/TNF-related protein 9 improves the anti-contractile effects of perivascular adipose tissue via the AMPK-eNOS pathway in diet-induced obese mice. Clin Exp Pharmacol Physiol 45, 50-57 (2018).

82 Sena, C. M., Pereira, A., Fernandes, R., Letra, L. \& Seica, R. M. Adiponectin improves endothelial function in mesenteric arteries of rats fed a high-fat diet: role of perivascular adipose tissue. Br J Pharmacol 174, 3514-3526 (2017).

83 Neves, K. B. et al. Chemerin reduces vascular nitric oxide/cGMP signalling in rat aorta: a link to vascular dysfunction in obesity? Clin Sci (Lond) 127, 111-122 (2014).

84 Lee, W. J. et al. Visfatin-induced expression of inflammatory mediators in human endothelial cells through the NF-kappaB pathway. Int J Obes (Lond) 33, 465-472 (2009).

85 Sweeney, G. Cardiovascular effects of leptin. Nat Rev Cardiol 7, 22-29 (2010).

86 Hubert, A. et al. Selective Deletion of Leptin Signaling in Endothelial Cells Enhances Neointima Formation and Phenocopies the Vascular Effects of Diet-Induced Obesity in Mice. Arterioscler Thromb Vasc Biol 37, 1683-1697 (2017).

87 Deiuliis, J. A. et al. Visceral Adipose MicroRNA 223 Is Upregulated in Human and Murine Obesity and Modulates the Inflammatory Phenotype of Macrophages. PLoS One 11, e0165962 (2016).

88 Mari-Alexandre, J. et al. Thickness and an Altered miRNA Expression in the Epicardial Adipose Tissue Is Associated With Coronary Heart Disease in Sudden Death Victims. Rev Esp Cardiol (Engl Ed) (2018). 
89 Renovato-Martins, M. et al. Microparticles derived from obese adipose tissue elicit a proinflammatory phenotype of CD16(+), CCR5(+) and TLR8(+) monocytes. Biochim Biophys Acta 1863, 139-151 (2017).

90 Ying, W. et al. Adipose Tissue Macrophage-Derived Exosomal miRNAs Can Modulate In Vivo and In Vitro Insulin Sensitivity. Cell 171, 372-384 e312 (2017).

91 Fischer, C. et al. A miR-327-FGF10-FGFR2-mediated autocrine signaling mechanism controls white fat browning. Nat Commun 8, 2079 (2017).

92 Icli, B. \& Feinberg, M. W. MicroRNAs in dysfunctional adipose tissue: cardiovascular implications. Cardiovasc Res 113, 1024-1034 (2017).

93 Kristensen, M. M. et al. miRNAs in human subcutaneous adipose tissue: Effects of weight loss induced by hypocaloric diet and exercise. Obesity (Silver Spring) 25, 572-580 (2017).

94 Candela, J., Wang, R. \& White, C. Microvascular Endothelial Dysfunction in Obesity Is Driven by Macrophage-Dependent Hydrogen Sulfide Depletion. Arterioscler Thromb Vasc Biol 37, 889-899 (2017).

95 Xia, N. et al. Uncoupling of Endothelial Nitric Oxide Synthase in Perivascular Adipose Tissue of Diet-Induced Obese Mice. Arterioscler Thromb Vasc Biol 36, 78-85 (2016).

96 Mikolajczyk, T. P. et al. Role of chemokine RANTES in the regulation of perivascular inflammation, T-cell accumulation, and vascular dysfunction in hypertension. FASEB $J \mathbf{3 0}$, 1987-1999 (2016).

97 Ruan, C. C. et al. Complement-mediated inhibition of adiponectin regulates perivascular inflammation and vascular injury in hypertension. Faseb j 31, 1120-1129 (2017).

98 Abu Bakar, H., Robert Dunn, W., Daly, C. \& Ralevic, V. Sensory innervation of perivascular adipose tissue: a crucial role in artery vasodilatation and leptin release. Cardiovasc Res 113, 962-972 (2017).

99 Antonopoulos, A. S. \& Antoniades, C. The role of epicardial adipose tissue in cardiac biology: classic concepts and emerging roles. J Physiol 595, 3907-3917 (2017).

100 Antonopoulos, A. S. et al. Mutual Regulation of Epicardial Adipose Tissue and Myocardial Redox State by PPAR-gamma/Adiponectin Signalling. Circ Res 118, 842-855 (2016).

101 Antoniades, C. et al. Myocardial redox state predicts in-hospital clinical outcome after cardiac surgery effects of short-term pre-operative statin treatment. J Am Coll Cardiol 59, 60-70 (2012).

102 Grunberg, J. R. et al. Overexpressing the novel autocrine/endocrine adipokine WISP2 induces hyperplasia of the heart, white and brown adipose tissues and prevents insulin resistance. Sci Rep 7, 43515 (2017).

103 Gao, W. et al. Retinol-Binding Protein 4 Induces Cardiomyocyte Hypertrophy by Activating TLR4/MyD88 Pathway. Endocrinology 157, 2282-2293 (2016).

104 Blumensatt, M. et al. Activin A impairs insulin action in cardiomyocytes via up-regulation of miR-143. Cardiovasc Res 100, 201-210 (2013).

105 Rodriguez-Penas, D. et al. The Adipokine Chemerin Induces Apoptosis in Cardiomyocytes. Cell Physiol Biochem 37, 176-192 (2015).

106 Blumensatt, M. et al. Secretory products from epicardial adipose tissue from patients with type 2 diabetes impair mitochondrial beta-oxidation in cardiomyocytes via activation of the cardiac renin-angiotensin system and induction of miR-208a. Basic Res Cardiol 112, 2 (2017).

107 Sawaki, D. et al. Visceral Adipose Tissue Drives Cardiac Aging Through Modulation of Fibroblast Senescence by Osteopontin Production. Circulation (2018).

108 Gutierrez-Tenorio, J. et al. The role of oxidative stress in the crosstalk between leptin and mineralocorticoid receptor in the cardiac fibrosis associated with obesity. Sci Rep 7, 16802 (2017).

109 Wang, Q. et al. The crucial role of activin A/ALK4 pathway in the pathogenesis of Ang-IIinduced atrial fibrosis and vulnerability to atrial fibrillation. Basic Res Cardiol 112, 47 (2017). 
110 Venteclef, N. et al. Human epicardial adipose tissue induces fibrosis of the atrial myocardium through the secretion of adipo-fibrokines. Eur Heart J 36, 795-805a (2015).

111 Bernasochi, G. B. et al. Pericardial adipose and aromatase: A new translational target for aging, obesity and arrhythmogenesis? J Mol Cell Cardiol 111, 96-101 (2017).

112 Haemers, P. et al. Atrial fibrillation is associated with the fibrotic remodelling of adipose tissue in the subepicardium of human and sheep atria. Eur Heart J 38, 53-61 (2017).

113 Jiang, D. S. et al. Aberrant Epicardial Adipose Tissue Extracellular Matrix Remodeling in Patients with Severe Ischemic Cardiomyopathy: Insight from Comparative Quantitative Proteomics. Sci Rep 7, 43787 (2017).

114 Salatzki, J. et al. Adipose tissue ATGL modifies the cardiac lipidome in pressure-overloadinduced left ventricular failure. PLoS Genet 14, e1007171 (2018).

115 Perez-Belmonte, L. M. et al. Expression of epicardial adipose tissue thermogenic genes in patients with reduced and preserved ejection fraction heart failure. Int J Med Sci 14, 891-895 (2017).

116 Takaoka, M. et al. Endovascular injury induces rapid phenotypic changes in perivascular adipose tissue. Arterioscler Thromb Vasc Biol 30, 1576-1582 (2010).

117 Cybularz, M. et al. Endothelial function and gene expression in perivascular adipose tissue from internal mammary arteries of obese patients with coronary artery disease. Atheroscler Supp/ 30, 149-158 (2017).

118 Antonopoulos, A. S. et al. Detecting human coronary inflammation by imaging perivascular fat. Sci Transl Med 9 (2017).

119 Liu, D., Ceddia, R. P. \& Collins, S. Cardiac natriuretic peptides promote adipose 'browning' through mTOR complex-1. Mol Metab (2018).

120 Wu, W. et al. Enhancing natriuretic peptide signaling in adipose tissue, but not in muscle, protects against diet-induced obesity and insulin resistance. Sci Signal 10 (2017).

121 Suffee, N. et al. Atrial natriuretic peptide regulates adipose tissue accumulation in adult atria. Proc Natl Acad Sci U S A 114, E771-e780 (2017).

122 Di Costanzo, A. et al. Non-alcoholic fatty liver disease and subclinical atherosclerosis: A comparison of metabolically- versus genetically-driven excess fat hepatic storage. Atherosclerosis 257, 232-239 (2017).

123 Targher, G., Byrne, C. D., Lonardo, A., Zoppini, G. \& Barbui, C. Non-alcoholic fatty liver disease and risk of incident cardiovascular disease: A meta-analysis. J Hepatol 65, 589-600 (2016).

124 Levelt, E. et al. Ectopic and Visceral Fat Deposition in Lean and Obese Patients With Type 2 Diabetes. J Am Coll Cardiol 68, 53-63 (2016).

125 Fabbrini, E. et al. Intrahepatic fat, not visceral fat, is linked with metabolic complications of obesity. Proc Natl Acad Sci U S A 106, 15430-15435 (2009).

126 Adolph, T. E., Grander, C., Grabherr, F. \& Tilg, H. Adipokines and Non-Alcoholic Fatty Liver Disease: Multiple Interactions. Int J Mol Sci 18 (2017).

127 Terry, J. G. et al. Intermuscular Adipose Tissue and Subclinical Coronary Artery Calcification in Midlife: The CARDIA Study (Coronary Artery Risk Development in Young Adults). Arterioscler Thromb Vasc Biol 37, 2370-2378 (2017).

128 Dale, C. E. et al. Causal Associations of Adiposity and Body Fat Distribution With Coronary Heart Disease, Stroke Subtypes, and Type 2 Diabetes Mellitus: A Mendelian Randomization Analysis. Circulation 135, 2373-2388 (2017).

129 Chandra, A. et al. The relationship of body mass and fat distribution with incident hypertension: observations from the Dallas Heart Study. J Am Coll Cardiol 64, 997-1002 (2014).

130 Neeland, I. J. et al. Body fat distribution and incident cardiovascular disease in obese adults. J Am Coll Cardiol 65, 2150-2151 (2015).

131 Mancio, J. et al. Epicardial adipose tissue volume assessed by computed tomography and coronary artery disease: a systematic review and meta-analysis. Eur Heart J Cardiovasc Imaging (2017). 
132 Heckbert, S. R. et al. Pericardial fat volume and incident atrial fibrillation in the Multi-Ethnic Study of Atherosclerosis and Jackson Heart Study. Obesity (Silver Spring) 25, 1115-1121 (2017).

133 Lazaros, G. et al. Prognostic implications of epicardial fat volume quantification in acute pericarditis. Eur J Clin Invest 47, 129-136 (2017).

134 Takx, R. A. et al. Supraclavicular Brown Adipose Tissue 18F-FDG Uptake and Cardiovascular Disease. J Nucl Med 57, 1221-1225 (2016).

135 Hung, W. C. et al. Plasma visfatin levels are associated with major adverse cardiovascular events in patients with acute ST-elevation myocardial infarction. Clin Invest Med 38, E100-109 (2015).

136 Lemieux, I. et al. Hypertriglyceridemic waist: A marker of the atherogenic metabolic triad (hyperinsulinemia; hyperapolipoprotein B; small, dense LDL) in men? Circulation 102, 179-184 (2000).

137 Kaul, S. et al. Dual-energy X-ray absorptiometry for quantification of visceral fat. Obesity (Silver Spring) 20, 1313-1318 (2012).

138 lacobellis, G. et al. Echocardiographic epicardial adipose tissue is related to anthropometric and clinical parameters of metabolic syndrome: a new indicator of cardiovascular risk. J Clin Endocrinol Metab 88, 5163-5168 (2003).

139 Davidovich, D., Gastaldelli, A. \& Sicari, R. Imaging cardiac fat. Eur Heart J Cardiovasc Imaging 14, 625-630 (2013).

140 Verma, S. K. et al. Differentiating brown and white adipose tissues by high-resolution diffusion NMR spectroscopy. J Lipid Res 58, 289-298 (2017).

141 Mazurek, T. et al. PET/CT evaluation of (18)F-FDG uptake in pericoronary adipose tissue in patients with stable coronary artery disease: Independent predictor of atherosclerotic lesions' formation? J Nucl Cardiol 24, 1075-1084 (2017).

142 Ohyama, K. et al. Association of Coronary Perivascular Adipose Tissue Inflammation and DrugEluting Stent-Induced Coronary Hyperconstricting Responses in Pigs: (18)FFluorodeoxyglucose Positron Emission Tomography Imaging Study. Arterioscler Thromb Vasc Biol 37, 1757-1764 (2017).

143 Ohyama, K. et al. Coronary Adventitial and Perivascular Adipose Tissue Inflammation in Patients With Vasospastic Angina. J Am Coll Cardiol 71, 414-425 (2018).

144 Cote, J. A. et al. Computed tomography-measured adipose tissue attenuation and area both predict adipocyte size and cardiometabolic risk in women. Adipocyte 5, 35-42 (2016).

145 Ganesan, G. et al. Diffuse optical spectroscopic imaging of subcutaneous adipose tissue metabolic changes during weight loss. Int J Obes (Lond) 40, 1292-1300 (2016).

146 Dinish, U. S. et al. Diffuse Optical Spectroscopy and Imaging to Detect and Quantify Adipose Tissue Browning. Sci Rep 7, 41357 (2017).

147 Branca, R. T. et al. Accurate quantification of brown adipose tissue mass by xenon-enhanced computed tomography. Proc Natl Acad Sci U S A 115, 174-179 (2018).

148 Farb, M. G., Park, S. Y., Karki, S. \& Gokce, N. Assessment of Human Adipose Tissue Microvascular Function Using Videomicroscopy. J Vis Exp (2017).

149 Investigators, O. T. et al. Basal insulin and cardiovascular and other outcomes in dysglycemia. N Engl J Med 367, 319-328 (2012).

150 Marso, S. P. et al. Liraglutide and Cardiovascular Outcomes in Type 2 Diabetes. N Engl J Med 375, 311-322 (2016).

151 Green, J. B. et al. Effect of Sitagliptin on Cardiovascular Outcomes in Type 2 Diabetes. N Engl J Med 373, 232-242 (2015).

152 Zinman, B. et al. Empagliflozin, Cardiovascular Outcomes, and Mortality in Type 2 Diabetes. $N$ Engl J Med 373, 2117-2128 (2015).

153 lacobellis, G., Mohseni, M., Bianco, S. D. \& Banga, P. K. Liraglutide causes large and rapid epicardial fat reduction. Obesity (Silver Spring) 25, 311-316 (2017). 
154 Lamers, D. et al. Dipeptidyl peptidase 4 is a novel adipokine potentially linking obesity to the metabolic syndrome. Diabetes 60, 1917-1925 (2011).

155 Zhuge, F. et al. DPP-4 Inhibition by Linagliptin Attenuates Obesity-Related Inflammation and Insulin Resistance by Regulating M1/M2 Macrophage Polarization. Diabetes 65, 2966-2979 (2016).

156 Marques, A. P. et al. Dipeptidyl peptidase IV (DPP-IV) inhibition prevents fibrosis in adipose tissue of obese mice. Biochim Biophys Acta 1862, 403-413 (2018).

157 Kim Chung le, T. et al. Exendin-4, a GLP-1 receptor agonist, directly induces adiponectin expression through protein kinase A pathway and prevents inflammatory adipokine expression. Biochem Biophys Res Commun 390, 613-618 (2009).

$158 \mathrm{Xu}, \mathrm{F}$. et al. GLP-1 receptor agonist promotes brown remodelling in mouse white adipose tissue through SIRT1. Diabetologia 59, 1059-1069 (2016).

159 Kosi-Trebotic, L. et al. Gliptin therapy reduces hepatic and myocardial fat in type 2 diabetic patients. Eur J Clin Invest 47, 829-838 (2017).

160 Diaz-Rodriguez, E. et al. Effects of dapagliflozin on human epicardial adipose tissue: modulation of insulin resistance, inflammatory chemokine production, and differentiation ability. Cardiovasc Res 114, 336-346 (2018).

161 Sato, T. et al. The effect of dapagliflozin treatment on epicardial adipose tissue volume. Cardiovasc Diabetol 17, 6 (2018).

162 Neeland, I. J. et al. Dysfunctional adiposity and the risk of prediabetes and type 2 diabetes in obese adults. JAMA 308, 1150-1159 (2012).

163 Nissen, S. E. \& Wolski, K. Effect of rosiglitazone on the risk of myocardial infarction and death from cardiovascular causes. N Engl J Med 356, 2457-2471 (2007).

164 Quesada, I. et al. Vascular dysfunction elicited by a crosstalk between periaortic adipose tissue and the vascular wall is reversed by pioglitazone. Cardiovasc Ther (2018).

165 Kumar, D. et al. Saroglitazar reduces obesity and associated inflammatory consequences in murine adipose tissue. Eur J Pharmacol 822, 32-42 (2018).

166 Adams, M. et al. Activators of peroxisome proliferator-activated receptor gamma have depotspecific effects on human preadipocyte differentiation. J Clin Invest 100, 3149-3153 (1997).

167 Than, A. et al. Angiotensin type 2 receptor activation promotes browning of white adipose tissue and brown adipogenesis. Signal Transduct Target Ther 2, 17022 (2017).

168 Sakaue, T. et al. Perivascular Adipose Tissue Angiotensin II Type 1 Receptor Promotes Vascular Inflammation and Aneurysm Formation. Hypertension 70, 780-789 (2017).

169 Jia, G. H. H., Aroor, A. R. \& Sowers, J. R. The role of mineralocorticoid receptor signaling in the cross-talk between adipose tissue and the vascular wall. Cardiovasc Res 113, 1055-1063 (2017).

170 Skiba, D. S. et al. Anti-atherosclerotic effect of the angiotensin 1-7 mimetic AVE0991 is mediated by inhibition of perivascular and plaque inflammation in early atherosclerosis. $\mathrm{Br} \mathrm{J}$ Pharmacol 174, 4055-4069 (2017).

171 Hoeke, G. et al. Atorvastatin accelerates clearance of lipoprotein remnants generated by activated brown fat to further reduce hypercholesterolemia and atherosclerosis. Atherosclerosis 267, 116-126 (2017).

172 Ridker, P. M. et al. Antiinflammatory Therapy with Canakinumab for Atherosclerotic Disease. N Engl J Med 377, 1119-1131 (2017).

173 Markus, M. R. et al. Changes in Body Weight and Composition Are Associated With Changes in Left Ventricular Geometry and Function in the General Population: SHIP (Study of Health in Pomerania). Circ Cardiovasc Imaging 10, e005544 (2017).

174 Amor, S. et al. Study of insulin vascular sensitivity in aortic rings and endothelial cells from aged rats subjected to caloric restriction: Role of perivascular adipose tissue. Exp Gerontol (2017). 
$175 \mathrm{Kim}, \mathrm{K}$. H. et al. Intermittent fasting promotes adipose thermogenesis and metabolic homeostasis via VEGF-mediated alternative activation of macrophage. Cell Res 27, 1309-1326 (2017).

176 Araujo, H. N. et al. Anti-contractile effects of perivascular adipose tissue in thoracic aorta from rats fed a high-fat diet: role of aerobic exercise training. Clin Exp Pharmacol Physiol 45, 293302 (2018).

177 Khoo, J. et al. Exercise-Induced Weight Loss Is More Effective Than Dieting for Improving Adipokine Profile, Insulin Resistance, and Inflammation in Obese Men. International Journal of Sport Nutrition and Exercise Metabolism 25, 566-575 (2015).

178 Ross, R. et al. Reduction in obesity and related comorbid conditions after diet-induced weight loss or exercise-induced weight loss in men. A randomized, controlled trial. Ann Intern Med 133, 92-103 (2000).

179 Maillard, F., Pereira, B. \& Boisseau, N. Effect of High-Intensity Interval Training on Total, Abdominal and Visceral Fat Mass: A Meta-Analysis. Sports Med 48, 269-288 (2018).

180 Dias, K. A. et al. Effect of High-Intensity Interval Training on Fitness, Fat Mass and Cardiometabolic Biomarkers in Children with Obesity: A Randomised Controlled Trial. Sports Med 48, 733-746 (2018).

181 Quist, J. S. et al. Effects of active commuting and leisure-time exercise on fat loss in women and men with overweight and obesity: a randomized controlled trial. Int J Obes (Lond) (2017).

182 Schauer, P. R. et al. Bariatric Surgery versus Intensive Medical Therapy for Diabetes - 5-Year Outcomes. N Engl J Med 376, 641-651 (2017).

183 Adams, T. D. et al. Weight and Metabolic Outcomes 12 Years after Gastric Bypass. N Engl J Med 377, 1143-1155 (2017).

184 Salehi, M., Prigeon, R. L. \& D'Alessio, D. A. Gastric bypass surgery enhances glucagon-like peptide 1-stimulated postprandial insulin secretion in humans. Diabetes 60, 2308-2314 (2011).

185 Frikke-Schmidt, H. et al. Weight loss independent changes in adipose tissue macrophage and T cell populations after sleeve gastrectomy in mice. Mol Metab 6, 317-326 (2017).

186 Hoffstedt, J. et al. Long-term Protective Changes in Adipose Tissue After Gastric Bypass. Diabetes Care 40, 77-84 (2017).

187 De Matteis, R. et al. Exercise as a new physiological stimulus for brown adipose tissue activity. Nutr Metab Cardiovasc Dis 23, 582-590 (2013).

188 Barquissau, V. et al. Caloric Restriction and Diet-Induced Weight Loss Do Not Induce Browning of Human Subcutaneous White Adipose Tissue in Women and Men with Obesity. Cell Rep 22, 1079-1089 (2018).

189 Tsiloulis, T. et al. No evidence of white adipocyte browning after endurance exercise training in obese men. Int J Obes (Lond) (2017).

190 Vosselman, M. J. et al. Low brown adipose tissue activity in endurance-trained compared with lean sedentary men. Int J Obes (Lond) 39, 1696-1702 (2015).

191 Seki, T. et al. Ablation of endothelial VEGFR1 improves metabolic dysfunction by inducing adipose tissue browning. J Exp Med 215, 611-626 (2018).

192 Wang, B. et al. Retinoic acid induces white adipose tissue browning by increasing adipose vascularity and inducing beige adipogenesis of PDGFRalpha(+) adipose progenitors. Cell Discov 3, 17036 (2017).

193 Oguri, Y. et al. Tetrahydrobiopterin activates brown adipose tissue and regulates systemic energy metabolism. JCl Insight 2 (2017).

194 Broeders, E. P. et al. Thyroid Hormone Activates Brown Adipose Tissue and Increases NonShivering Thermogenesis--A Cohort Study in a Group of Thyroid Carcinoma Patients. PLoS One 11, e0145049 (2016).

195 Cypess, A. M. et al. Activation of human brown adipose tissue by a beta3-adrenergic receptor agonist. Cell Metab 21, 33-38 (2015). 
196 Xue, Y., Xu, X., Zhang, X. Q., Farokhzad, O. C. \& Langer, R. Preventing diet-induced obesity in mice by adipose tissue transformation and angiogenesis using targeted nanoparticles. Proc Natl Acad Sci U S A 113, 5552-5557 (2016).

197 Cui, X. et al. Exosomes From Adipose-derived Mesenchymal Stem Cells Protect the Myocardium Against Ischemia/Reperfusion Injury Through Wnt/beta-Catenin Signaling Pathway. J Cardiovasc Pharmacol 70, 225-231 (2017).

198 Schenke-Layland, K. et al. Adipose tissue-derived cells improve cardiac function following myocardial infarction. J Surg Res 153, 217-223 (2009).

199 Bobi, J. et al. Intracoronary Administration of Allogeneic Adipose Tissue-Derived Mesenchymal Stem Cells Improves Myocardial Perfusion But Not Left Ventricle Function, in a Translational Model of Acute Myocardial Infarction. J Am Heart Assoc 6 (2017).

\section{Acknowledgements}

E.K.O. receives support from the A.G. Leventis Foundation. C.A. received funding from the British Heart Foundation (FS/16/15/32047 and TG/16/3/32687), the National Institute for Health Research (NIHR) Oxford Biomedical Research Centre, and the Novo Nordisk Foundation (NNF15CC0018486).

\section{Author contributions:}

E. K. O. performed the literature review and prepared the figures and tables and wrote the manuscript before submission. C. A. provided scientific direction, and wrote and reviewed the manuscript before submission.

\section{Competing interests}

The methods for analysis of perivascular Fat Attenuation Index described in this manuscript are subject to patent applications, numbers PCT/GB2015/052359 and PCT/GB2017/053262. C.A. is a founder and shareholder of Caristo Diagnostics, a CT-image analysis company. C.A. has received research funding from Sanofi and Novo Nordisk, and a consultancy fee from Mitsubishi-Tanabe.

\section{Publisher's note}

Springer Nature remains neutral with regard to jurisdictional claims in published maps and institutional affiliations.

\section{Key points}

- The adipose tissue is a crucial regulator of cardiovascular health and exerts both protective and deleterious effects on the cardiovascular system. 
- The biological profile of the adipose tissue largely depends on its expansion, body distribution, quality, and differences in local biology.

- The adipose tissue can affect local cardiovascular biology through the secretion of adipocytokines with endocrine and/or paracrine effects.

- Conversely, pro-inflammatory and oxidative stimuli in diseased vessels and/or myocardium can modify adipose tissue biology, suggesting a bidirectional interplay between the adipose tissue and the cardiovascular system.

- Several traditional and experimental imaging modalities can be exploited to characterise both quantitative and qualitative adipose tissue features with important implications in cardiometabolic risk stratification.

- The adipose tissue represents a promising therapeutic target in cardiovascular therapeutics and might mediate the cardiovascular benefit observed with different pharmacological, lifestyle, and other interventions.

Figure 1. Effects of the adipose tissue in the cardiovascular system. The adipose tissue exerts direct effects on the cardiovascular system through the secretion of a wide range of bioactive products, including adipocytokines, microvesicles, inorganic molecules, and reactive oxygen species. a | Adipose tissue products from remote depots, such as the subcutaneous adipose tissue (SAT), are released into the bloodstream through the adipose tissue microvessels and can reach distant sites (such as the heart and arteries) where they exert their biological effects in an endocrine manner. $\mathbf{b} \mid$ In addition to these endocrine effects, perivascular adipose tissue (PVAT) and epicardial adipose tissue (EAT) can exert direct effects on the adjacent vascular wall or myocardium, respectively, through the paracrine release of bioactive mediators. Given that PVAT is often contiguous to the outer adventitial layer of the vascular wall, the vasa vasorum might mediate the local transport of these molecules. c | In some cases, PVAT-released products can reach the lumen of the adjacent vessel and travel downstream, thereby regulating the biology of entire vascular beds in a vasocrine manner.

Figure 2. Interplay between the adipose tissue and the vascular wall. The adipose tissue AT is involved in a bidirectional interplay with the vascular wall, mediated by the release of several products with endocrine (by release into the systemic bloodstream) and/or paracrine (local) effects. Among all 
adipose tissue depots, the perivascular adipose tissue (PVAT) is now recognized as crucial regulator of vascular biology, given its anatomical proximity to the vessels that facilitates paracrine interactions. a | The adipose tissue releases a range of bioactive products, including adipokines (such as adiponectin, leptin, and resistin), chemokines, cytokines, gaseous messengers such as hydrogen sulphide $\left(\mathrm{H}_{2} \mathrm{~S}\right)$ and nitric oxide (NO), fatty acids such as palmitic acid methyl ester (PAME), reactive oxygen species, and microparticles that can carry microRNAs and other molecules to the adjacent vessel. $\mathbf{b}$ | Inside the vascular wall, these molecules have pleiotropic effects on multiple targets and have been involved in the regulation of local redox state (through modulation of NADPH-oxidase activity and endothelial NO synthase (eNOS) coupling), endothelial function (through regulation of eNOS activity and NO bioavailability), local endothelial cell activation, inflammation (such as the regulation of M1/M2 macrophage polarization), vascular smooth muscle cell (VSMC) migration, neointima formation, and vascular tone. c | In addition to these outside-to-inside signals, vascular inflammation and oxidative stress can also affect the adipose tissue (particularly PVAT) biology in an inside-to-outside manner. Inflammatory signals (such as pro-inflammatory cytokines) or lipid peroxidation products (such as 4hydroxynonenal) can diffuse to the adjacent PVAT and activate signalling pathways in adipocytes. RAAS, renin-angiotensin-aldosterone system.

Figure 3. Interplay between the adipose tissue and the myocardium. A continuous crosstalk exists between the myocardium and the adipose tissue. Remote adipose tissue depots can modify cardiac biology through the release of bioactive products into the bloodstream (endocrine signalling). The epicardial adipose tissue (EAT), the adipose tissue layer that lies on the surface of the human heart inside the visceral pericardium, also interacts with adjacent cardiomyocytes and extracellular matrix in a paracrine manner. The EAT effects on cardiac biology largely depend on the nature of its secretome, which is characterised by a wide range of products, including adipocytokines, microparticles, gaseous messengers, and lipids. Systemic factors, such as obesity, systemic inflammation, and insulin resistance, are important modifiers of the adipose tissue secretome and can shift the balance towards the secretion of products with deleterious cardiac effects. Adipose tissuederived molecules are involved in several biological processes in the myocardium, such as hypertrophy, redox balance, contractility, inflammation, and fibrosis, and in clinical conditions such as arrhythmogenesis and heart failure. The EAT also offers mechanical protection and metabolic support, for example, in the form of free fatty acids (FFA), to the adjacent myocardium. Inside-to-outside signalling from the myocardium to the EAT also occurs. For example, natriuretic peptides upregulate adiponectin biosynthesis and possibly induce adipose tissue browning. Lipid peroxidation products generated in states of increased myocardial oxidative stress can diffuse to the surrounding EAT, 
increasing adiponectin biosynthesis through the activation of peroxisome proliferator activated receptor- $\gamma$ (PPAR $\gamma)$, and adiponectin then exerts antioxidant effects on the myocardium in a protective paracrine loop. In heart failure, inflammatory mediators including IL-6 and tumor necrosis factor (TNF) released from the diseased myocardium can trigger EAT lipolysis, contributing to the cardiac cachexia and decreased EAT volume observed in patients with heart failure. GLUT4, glucose transporter type 4; $\mathrm{H}_{2} \mathrm{~S}$, hydrogen sulphide; NO, nitric oxide.

Figure 4. Noninvasive imaging for adipose tissue phenotyping. Adipose tissue dysfunction is implicated in a wide range of cardiometabolic abnormalities; however, adipose tissue characterization in the clinical setting is limited to measurement of simple anthropometric indices, predominantly BMI. Unfortunately, the BMI does not capture important adipose tissue features, such as distribution, biology, and overall body fat composition. Alternative anthropometric measurements, such as Waistto-Hip ratio (WHR) and Waist-to-Height ratio (WHtR) are more appropriate obesity indices of cardiometabolic risk than $\mathrm{BMI}$, but still do not provide important information on adipose tissue biology and visceral distribution. Several widely-used clinical imaging modalities can be employed to provide this information, with each modality having its relative advantages (green box) and limitations (red box) compared with the others. a | Ultrasound is a safe and widely available method to assess thickness of superficial adipose tissue layers, such as femoral, abdominal, and subcutaneous adipose tissue (SAT), or even epicardial adipose tissue (EAT). However, ultrasound is subject to operatordependent variability and cannot provide information on most visceral adipose tissue (VAT) depots. These limitations are overcome by CT imaging and MRI. $\mathbf{b}$ | CT has high accuracy and reproducibility for quantitative adipose tissue characterization and can also provide qualitative information by means of adipose tissue CT signal attenuation. CT can be combined with angiography of vascular beds, allowing tracking and characterization of perivascular adipose tissue (PVAT). Novel PVAT characterization algorithms on coronary $\mathrm{CT}$ angiography can extract information on coronary inflammation. c | MRI is associated with longer acquisition times, higher costs, and less availability, but avoids ionising radiation exposure and can provide functional information through combination with, for example, proton spectroscopy. d | MRI and CT can be combined with PET to extract functional information, for example, on adipose tissue inflammation or browning, by the administration of appropriate radiotracers, most commonly ${ }^{18} \mathrm{~F}$-fludeoxyglucose, at the cost of increased radiation exposure, long acquisition times, and often poor spatial resolution. 
Table 1. Adipose tissue products and their effects on the cardiovascular system.

\begin{tabular}{|c|c|c|c|c|}
\hline \multirow[t]{2}{*}{$\begin{array}{l}\text { Adipose tissue } \\
\text { product }\end{array}$} & \multicolumn{2}{|c|}{$\begin{array}{l}\text { Levels versus } \\
\text { healthy } \\
\text { conditions }\end{array}$} & \multirow[t]{2}{*}{$\begin{array}{l}\text { Effects on the } \\
\text { cardiovascular } \\
\text { system }^{\text {a }}\end{array}$} & \multirow[t]{2}{*}{ Examples of suggested mechanisms $\mathrm{s}^{\mathrm{a}}$} \\
\hline & Obesity & IR/DM & & \\
\hline \multicolumn{5}{|l|}{ Adipokines } \\
\hline Activin A & 个/- & 个/- & $\begin{array}{l}\text { Pro-fibrotic and } \uparrow \\
\text { IR }\end{array}$ & $\begin{array}{l}\text { - Promotes fibrosis (might be } \\
\text { mediated by angiotensin II), which } \\
\text { is linked to arrhythmogenicity }\end{array}$ \\
\hline Adiponectin & $\downarrow$ & $\downarrow$ & $\begin{array}{l}\text { Anti-oxidant, anti- } \\
\text { inflammatory, and } \\
\downarrow I R\end{array}$ & $\begin{array}{l}\text { - } \downarrow \text { NF-KB signalling } \\
\text { - } \uparrow \text { AMPK and AKT signalling } \\
\text { - } \downarrow \text { NADPH oxidase activity ( } \downarrow \\
\text { p47 phox/RAC1 translocation) } \\
-\uparrow \text { eNOS phosphorylation and } \\
\text { coupling ( } \uparrow \mathrm{BH}_{4} \text { bioavailability) }\end{array}$ \\
\hline $\begin{array}{l}\text { Angiotensinogen/ } \\
\text { angiotensin } \\
\text { II/aldosterone }\end{array}$ & $\uparrow$ & $\uparrow$ & $\begin{array}{l}\text { Pro-oxidant, pro- } \\
\text { inflammatory, and } \\
\text { pro-fibrotic }\end{array}$ & $\begin{array}{l}\text { - } \uparrow \text { NF-KB signalling (angiotensin II) } \\
\text { - } \uparrow \quad \mathrm{NADPH} \text { oxidase activity } \\
\text { (angiotensin II) }\end{array}$ \\
\hline Apelin & $\uparrow$ & $\uparrow$ & $\begin{array}{l}\text { Pro-oxidant and } \\
\text { pro-inflammatory }\end{array}$ & $\begin{array}{l}\text { - } \uparrow \text { NADPH oxidase activity ( } \uparrow \\
\text { subunit expression) }\end{array}$ \\
\hline Chemerin & $\uparrow$ & $\uparrow$ & $\begin{array}{l}\text { Pro-oxidant and } \\
\text { pro-inflammatory }\end{array}$ & $\begin{array}{l}\text { - } \uparrow \text { eNOS expression, but } \uparrow \text { eNOS } \\
\text { uncoupling }\end{array}$ \\
\hline Leptin & $\uparrow$ & $\uparrow$ & $\begin{array}{l}\text { Pro-oxidant and } \\
\text { other pleiotropic } \\
\text { effects }\end{array}$ & $\begin{array}{l}\text { - } \uparrow \text { NADPH oxidase activity ( } \\
\text { p44 } \\
\text { - } \uparrow \text { Mitochon activation) } \\
\text { - } \uparrow \text { eNOS expression ROS generation }\end{array}$ \\
\hline Omentin 1 & $\downarrow$ & $\downarrow$ & $\begin{array}{l}\text { Anti-oxidant, anti- } \\
\text { inflammatory, and } \\
\downarrow \text { IR }\end{array}$ & $\begin{array}{l}-\downarrow \text { NADPH oxidase activity ( } \downarrow \\
\text { p47 } \\
\bullet \downarrow \text { TNFox activation) } \\
\end{array}$ \\
\hline Resistin & $\uparrow$ & $\uparrow$ & $\begin{array}{l}\text { Pro-oxidant, pro- } \\
\text { inflammatory, and } \\
\uparrow I R\end{array}$ & $\begin{array}{l}\text { - } \uparrow \text { NADPH oxidase activity ( } \\
\text { p4 } 47^{\text {phox }} \text { activation) } \\
-\downarrow \text { eNOS expression }\end{array}$ \\
\hline $\begin{array}{l}\text { Retinol-binding } \\
\text { protein } 4\end{array}$ & 个/- & 个/- & $\begin{array}{l}\text { Pro-oxidant, pro- } \\
\text { inflammatory, } \uparrow I R\end{array}$ & $\begin{array}{l}\text { - } \uparrow ~ N F-K B \text { signalling } \\
\text { - } \uparrow \text { NADPH oxidase activity } \\
\text { - } \uparrow \text { Cell-adhesion molecules (such } \\
\text { as VCAM1) }\end{array}$ \\
\hline Visfatin & 个/- & 个/- & $\begin{array}{l}\text { Pro-oxidant, (pro- } \\
\text { inflammatory) }\end{array}$ & $\begin{array}{l}\text { - } \uparrow \text { NF-KB signalling } \\
\text { - } \uparrow \text { NADPH oxidase activity } \\
\text { - } \uparrow \text { Cell-adhesion molecules (such } \\
\text { as VCAM1) }\end{array}$ \\
\hline \multicolumn{5}{|c|}{ Pro-inflammatory cytokines and chemokines } \\
\hline $\begin{array}{l}\text { For example, TNF } \\
\text { and IL-6 }\end{array}$ & $\uparrow$ & $\uparrow$ & $\begin{array}{l}\text { Pro-oxidant, pro- } \\
\text { inflammatory, and } \\
\uparrow I R\end{array}$ & $\begin{array}{l}\text { - } \uparrow \text { NADPH oxidase activity } \\
\text { - } \uparrow \text { Cell-adhesion molecules (such } \\
\text { as VCAM-1) }\end{array}$ \\
\hline \multicolumn{5}{|l|}{ Non-coding RNAs } \\
\hline microRNAs & 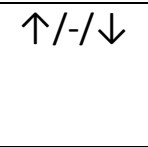 & $\begin{array}{l}\uparrow /- \\
/ \downarrow\end{array}$ & $\begin{array}{l}\text { Regulation of } \\
\text { inflammation, and } \\
\text { fibrosis, and VSMC }\end{array}$ & $\begin{array}{lc}- \text { Repress protein production } \\
\text { through binding and } \\
\text { destabilization of specific mRNAs }\end{array}$ \\
\hline
\end{tabular}




\begin{tabular}{|c|c|c|c|c|}
\hline & & & $\begin{array}{l}\text { activation and } \\
\text { migration }\end{array}$ & \\
\hline \multicolumn{5}{|c|}{ Gaseous messengers } \\
\hline $\begin{array}{l}\text { Hydrogen } \\
\text { sulphide }\end{array}$ & $\downarrow$ & $\downarrow$ & $\begin{array}{l}\text { Anti-oxidant, anti- } \\
\text { inflammatory, } \\
\text { vasodilatory, and } \\
\text { pro-angiogenic }\end{array}$ & $\begin{array}{l}\text { For example, activates ATP-regulated } \\
\text { potassium channels, which promotes } \\
\text { vasorelaxation }\end{array}$ \\
\hline Nitric oxide & $\downarrow$ & $\downarrow$ & $\begin{array}{l}\text { Anti-inflammatory } \\
\text { and vasodilatory }\end{array}$ & $\begin{array}{l}\text { - } \text { 个 cGMP in VSMCs, which leads to } \\
\text { 个 PKG and to vasorelaxation } \\
\text { - Further immunomodulatory } \\
\text { effects }\end{array}$ \\
\hline \multicolumn{5}{|c|}{ Reactive oxygen species } \\
\hline $\begin{array}{l}\text { Hydrogen } \\
\text { peroxide }\end{array}$ & $\uparrow /-$ & $\uparrow /-$ & $\begin{array}{l}\text { Pro-oxidant, pro- } \\
\text { inflammatory, } \\
\text { vasoactive, and } \\
\text { also involved in } \\
\text { signal transduction }\end{array}$ & $\begin{array}{l}\mathrm{H}_{2} \mathrm{O}_{2} \text { promotes vasorelaxation } \\
\text { through an endothelium- } \\
\text { independent mechanism }\end{array}$ \\
\hline \multicolumn{5}{|c|}{ Other products } \\
\hline Antibodies & $\begin{array}{l}\text { Not } \\
\text { known }\end{array}$ & $\begin{array}{l}\text { Not } \\
\text { known }\end{array}$ & $\begin{array}{l}\text { Anti-atherogenic or } \\
\text { pro-atherogenic }\end{array}$ & $\begin{array}{l}\text { For example, PVAT-residing } B_{1} \text { cells } \\
\text { produce IgM targeting oxidation- } \\
\text { specific epitopes on LDL. }\end{array}$ \\
\hline PAME & $\begin{array}{l}\text { Not } \\
\text { known }\end{array}$ & $\begin{array}{l}\text { Not } \\
\text { known }\end{array}$ & Vasodilatory & $\begin{array}{l}\text { For example, activates voltage- } \\
\text { dependent potassium channels, } \\
\text { which leads to vasorelaxation }\end{array}$ \\
\hline
\end{tabular}


aThe list of effects and mechanisms is not exhaustive, but rather aims to provide an overview of the major cardiovascular effects of adipose tissue-derived products. -, no change; AKT, RAC-alpha serine/threonineprotein kinase; $\mathrm{BH}_{4}$, tetrahydrobiopterin; $\mathrm{CGMP}$ : cyclic guanosine monophosphate; DM, diabetes mellitus; eNOS, endothelial nitric oxide synthase; IgM, immunoglobulin $M$; IR, insulin resistance; NADPH, nicotinamide adenine dinucleotide phosphate; NF-KB: nuclear factor-KB; PAME, palmitic acid methyl ester; PKG: protein kinase G; PVAT: perivascular adipose tissue; ROS, reactive oxygen species; TNF, tumour necrosis factor; VCAM1, vascular cell adhesion molecule 1; VSMC, vascular smooth muscle cell. 
Table 2. Non-invasive imaging modalities for adipose tissue phenotyping

\begin{tabular}{|c|c|c|c|c|c|c|c|c|c|}
\hline $\begin{array}{l}\text { Imaging } \\
\text { method }\end{array}$ & Methodology & $\begin{array}{l}\text { Ava } \\
\text { ilabi } \\
\text { lity }\end{array}$ & Cost & $\begin{array}{l}\text { Radi } \\
\text { atio } \\
n\end{array}$ & $\begin{array}{l}\text { Spatial } \\
\text { resolu } \\
\text { tion }\end{array}$ & $\begin{array}{l}\text { Operat } \\
\text { or } \\
\text { depen } \\
\text { dence }\end{array}$ & $\begin{array}{l}\text { Sca } \\
\text { nni } \\
\text { ng } \\
\text { tim } \\
\text { e }\end{array}$ & Strengths & Limitations \\
\hline $\begin{array}{l}\text { Dual } \\
\text { energy X- } \\
\text { ray } \\
\text { absorptio } \\
\text { metry } \\
\text { (DEXA) }\end{array}$ & $\begin{array}{l}\text { Measures fat } \\
\text { mass by } \\
\text { calculating the } \\
\text { differential } \\
\text { absorption of } \\
\text { two X-ray } \\
\text { beams at } \\
\text { different } \\
\text { energy levels. }\end{array}$ & +++ & + & + & + & + & + & $\begin{array}{l}\text { Rapid, low-cost, yet } \\
\text { crude assessment } \\
\text { of body } \\
\text { composition and } \\
\text { total and/or } \\
\text { visceral fat mass. }\end{array}$ & $\begin{array}{l}\text { Cannot easily } \\
\text { provide } \\
\text { detailed } \\
\text { information } \\
\text { on adipose } \\
\text { tissue } \\
\text { distribution } \\
\text { and specific } \\
\text { adipose } \\
\text { tissue } \\
\text { depots. }\end{array}$ \\
\hline Ultrasound & $\begin{array}{l}\text { Adipose tissue } \\
\text { appears as a } \\
\text { hypoechoic } \\
\text { space or } \\
\text { structure and } \\
\text { can be defined } \\
\text { based on } \\
\text { adjacent } \\
\text { structures and } \\
\text { probe } \\
\text { orientation. }\end{array}$ & +++ & + & - & + & +++ & + & $\begin{array}{l}\text { Easy, low-cost } \\
\text { method to } \\
\text { measure the } \\
\text { thickness of } \\
\text { accessible adipose } \\
\text { tissue depots (such } \\
\text { as abdominal and } \\
\text { gluteal SAT, and } \\
\text { EAT). } \\
\text { Measurements can } \\
\text { be collected from } \\
\text { routine clinical } \\
\text { scans (for example, } \\
\text { transthoracic } \\
\text { echocardiography). }\end{array}$ & $\begin{array}{l}\text { Relies } \\
\text { traditionally } \\
\text { on 2D (for } \\
\text { example, } \\
\text { thickness) } \\
\text { rather than } \\
\text { 3D } \\
\text { measuremen } \\
\text { ts (such as } \\
\text { volumes). } \\
\text { Operator } \\
\text { dependent. }\end{array}$ \\
\hline CT imaging & $\begin{array}{l}\text { Computer- } \\
\text { processed } \\
\text { combinations } \\
\text { of 3D X-ray } \\
\text { images, } \\
\text { producing } \\
\text { cross-sectional } \\
\text { images of the } \\
\text { body. } \\
\text { Application of } \\
\text { standardized } \\
\text { attenuation } \\
\text { thresholds (for } \\
\text { example, -190 } \\
\text { to -30 } \\
\text { Hounsfield } \\
\text { Units) allows } \\
\text { the segmentation } \\
\text { of adipose } \\
\text { tissue } \\
\text { structures. }\end{array}$ & +++ & ++ & ++ & +++ & + & + & 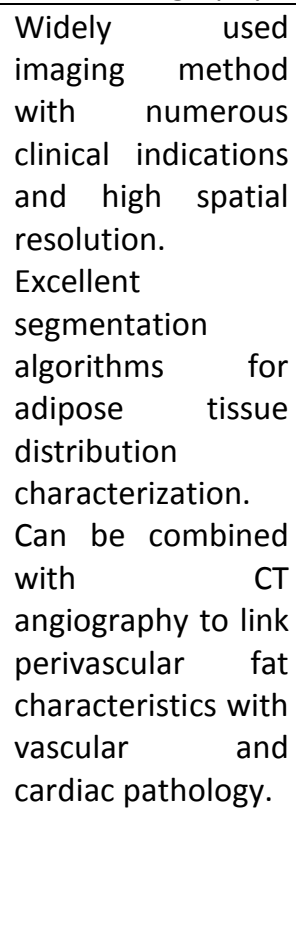 & $\begin{array}{l}\text { Radiation } \\
\text { exposure } \\
\text { (varies with } \\
\text { different } \\
\text { protocols). } \\
\text { Relies on } \\
\text { heavily used } \\
\text { equipment. }\end{array}$ \\
\hline
\end{tabular}




\begin{tabular}{|c|c|c|c|c|c|c|c|c|c|}
\hline MRI & $\begin{array}{l}\text { Various pulse } \\
\text { sequences can } \\
\text { be used to } \\
\text { separate } \\
\text { adipose tissue } \\
\text { from non- } \\
\text { adipose tissue } \\
\text { structures } \\
\text { (such as T1- } \\
\text { weighted and } \\
\text { T2-weighted } \\
\text { imaging, } \\
\text { chemical } \\
\text { (frequency)- } \\
\text { selective } \\
\text { imaging, and } \\
\text { chemical-shift } \\
\text { encoded } \\
\text { imaging) }\end{array}$ & + & +++ & - & ++ & + & ++ & $\begin{array}{l}\text { Excellent technique } \\
\text { that avoids } \\
\text { radiation exposure } \\
\text { and provides 3D } \\
\text { data on adipose } \\
\text { tissue distribution. } \\
\text { Chemical-shift } \\
\text { water-fat MRI or } \\
\text { combination with } \\
\text { proton } \\
\text { spectroscopy can } \\
\text { provide additional } \\
\text { functional } \\
\text { characterization } \\
\text { such as on adipose } \\
\text { tissue browning. }\end{array}$ & $\begin{array}{l}\text { Expensive } \\
\text { technique, } \\
\text { with limited } \\
\text { availability } \\
\text { and long } \\
\text { scanning } \\
\text { time. } \\
\text { Requires } \\
\text { appropriate } \\
\text { protocol } \\
\text { adjustments } \\
\text { to acquire } \\
\text { accurate } \\
\text { adipose } \\
\text { tissue } \\
\text { measuremen } \\
\text { ts. }\end{array}$ \\
\hline $\begin{array}{l}\text { PET-CT } \\
\text { and PET- } \\
\text { MRI }\end{array}$ & $\begin{array}{l}\text { Quantifies } \\
\text { radiotracer } \\
\text { uptake in a } \\
\text { volume of } \\
\text { interest, } \\
\text { guided by co- } \\
\text { registration of } \\
\text { the PET images } \\
\text { with CT or MRI } \\
\text { data. }\end{array}$ & + & +++ & +++ & + & + & +++ & $\begin{array}{l}\text { Hybrid PET-CT and } \\
\text { PET-MRI imaging } \\
\text { combines the } \\
\text { excellent spatial } \\
\text { resolution and } \\
\text { characterization of } \\
\text { CT and MRI imaging } \\
\text { with functional } \\
\text { information on } \\
\text { inflammatory and } \\
\text { metabolic activity } \\
\text { of adipose tissue by } \\
\text { means of } \\
\text { radiotracer uptake } \\
\text { (such as 18F- } \\
\text { fluorodeoxyglucos } \\
\text { e). }\end{array}$ & $\begin{array}{l}\text { Expensive } \\
\text { technique } \\
\text { with limited } \\
\text { availability, } \\
\text { poor spatial } \\
\text { resolution, } \\
\text { and high } \\
\text { radiation } \\
\text { exposure. }\end{array}$ \\
\hline
\end{tabular}

+, low; ++, medium; +++, high. 


\section{Glossary}

\section{Visceral adipose tissue (VAT)}

Adipose tissue surrounding the visceral organs in the thorax and abdomen, including fat in the omental and mesenteric peritoneal folds (omental/mesenteric adipose tissue), around the kidneys in the retroperitoneal space (perirenal adipose tissue), as well as epicardial, pericardial, and other depots.

\section{Epicardial adipose tissue (EAT)}

The adipose tissue layer that lies between the surface of the heart and the visceral pericardium.

\section{Pericardial adipose tissue (PAT)}

Adipose tissue layer located on the external surface of the parietal pericardium.

\section{White adipose tissue (WAT)}

The predominant adipose tissue type found in the human body, which is responsible for energy storage in the form of triglycerides and energy supply to peripheral tissues through regulated release of free fatty acids.

\section{Brown adipose tissue (BAT)}

A distinct, metabolically active adipose tissue phenotype, found predominantly in the interscapular and supraclavicular regions in humans, and involved in thermoregulatory thermogenesis.

\section{Beige adipose tissue}

Also known as brite adipose tissue; an inducible, brown-like adipose tissue phenotype, which is normally found interspersed in white adipose tissue depots.

\section{Ectopic fat}

Fat stored in tissues other than the adipose tissue that normally contain small amounts of fat, such as the heart, liver, and muscles.

\section{Adipocytokines}

A range of bioactive molecules secreted by various cell types found in the adipose tissue (such as adipocytes and stromal cells) that exert autocrine, paracrine, and endocrine effects on both the adipose and peripheral tissues.

\section{Perivascular adipose tissue (PVAT)}

Adipose tissue surrounding the vessels and is often contiguous to the outer adventitial layer. 


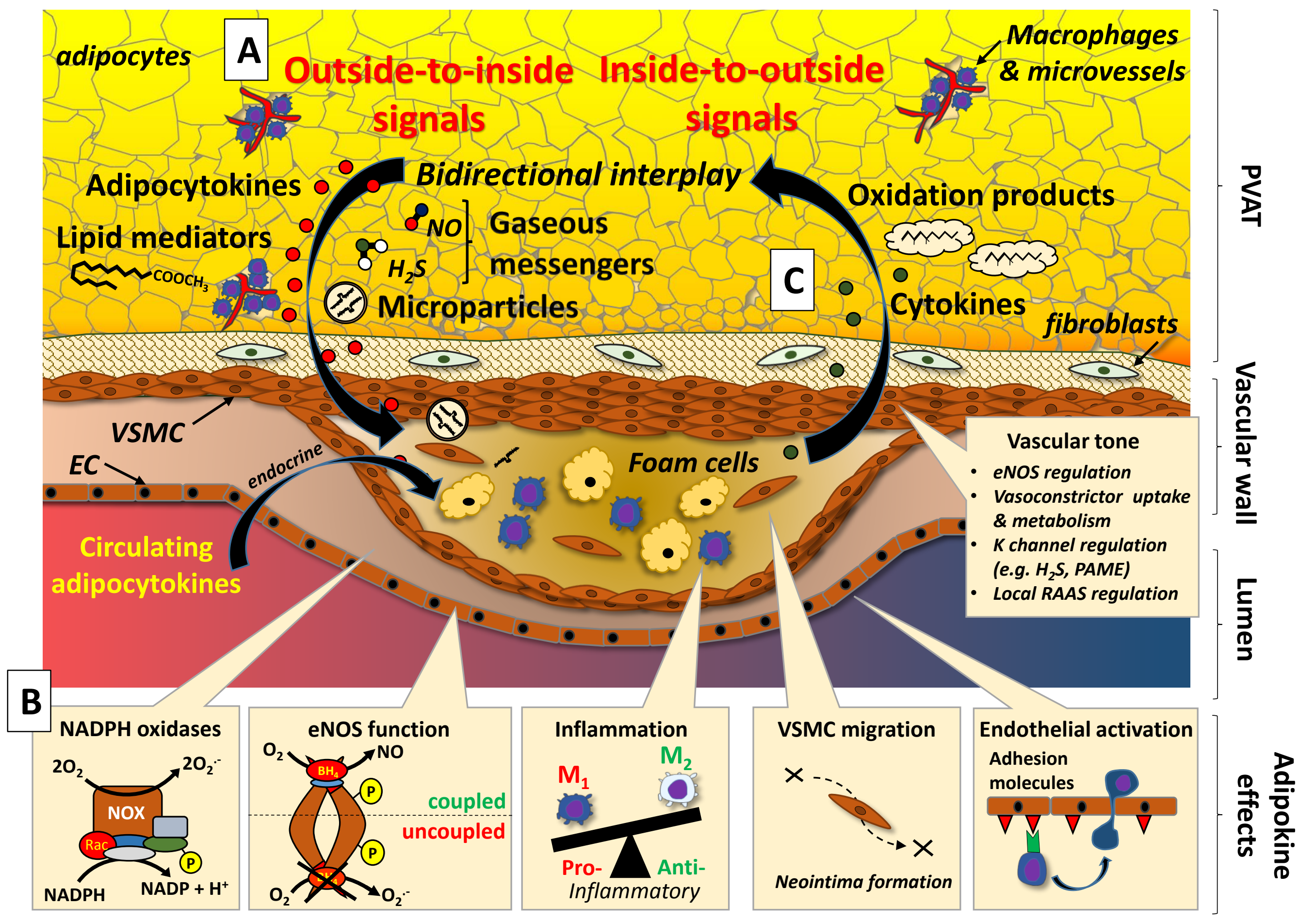


Hypertension,

Epicardial AT smoking, obesity etc.

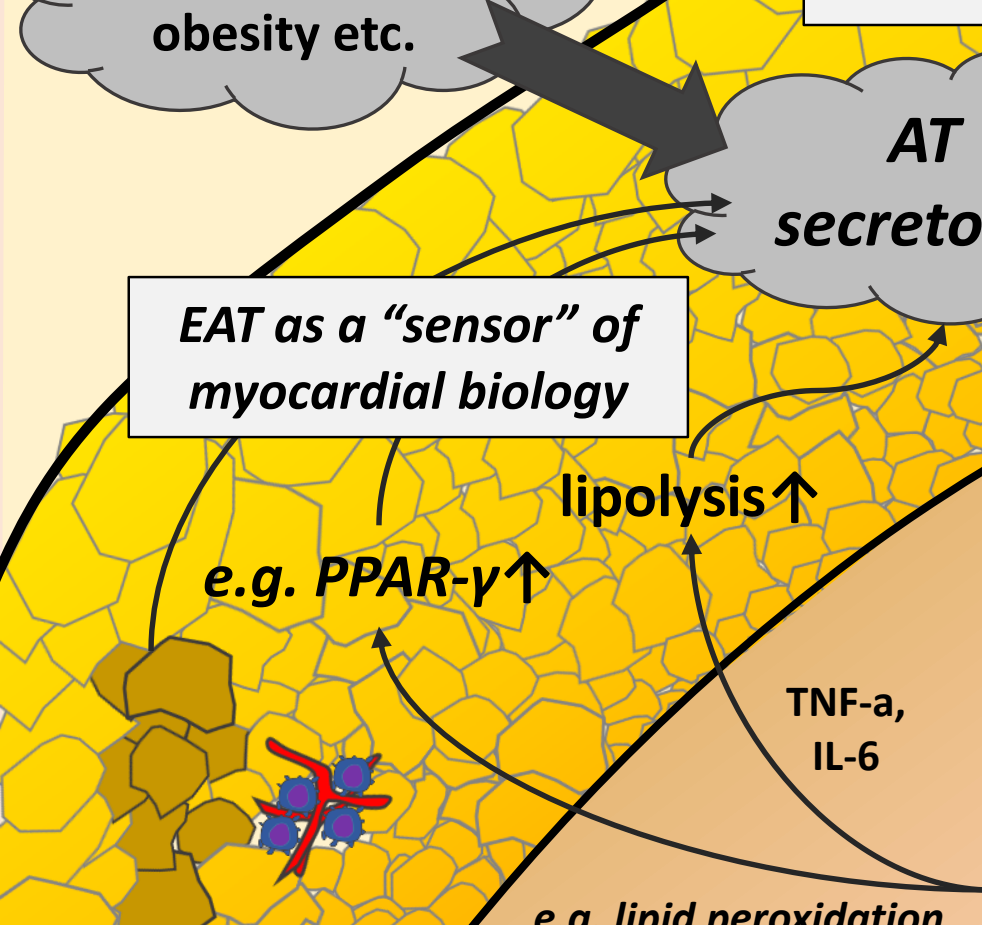

e.g. lipid peroxidation Mu products

\section{e.g. AT} browning

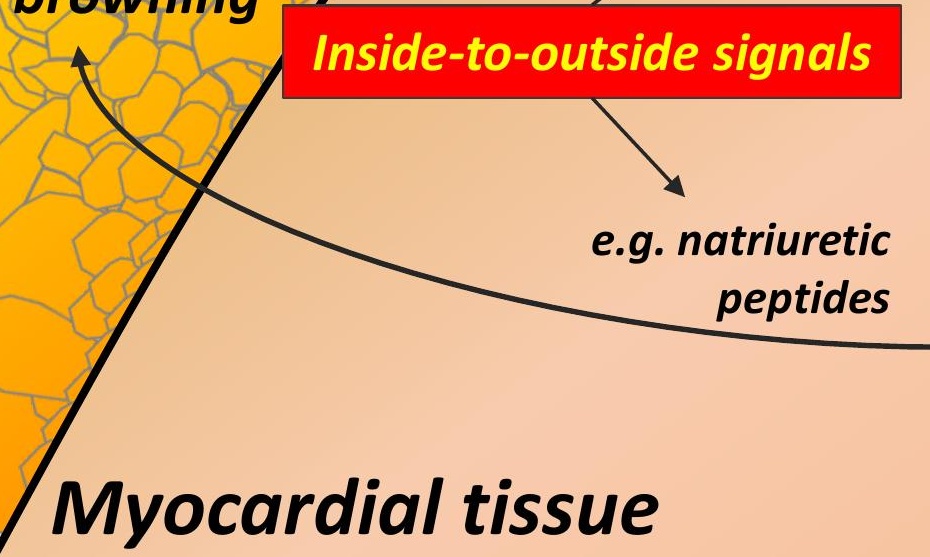

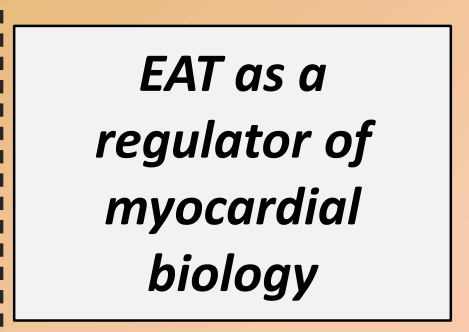
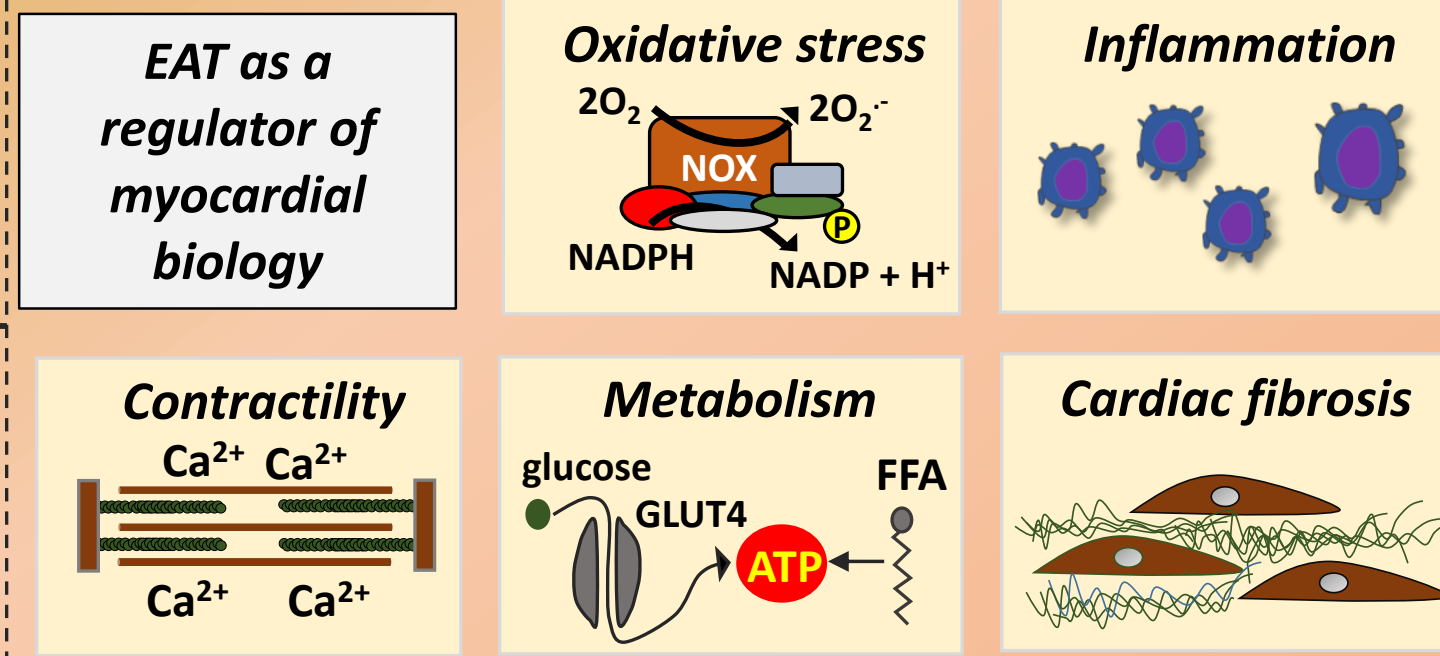

Lipotoxicity? Metabolic support?

\section{Outside-to-inside signals}

Adipocytokines, microparticles, miRNA, gaseous messengers $\left(H_{2} S, N O\right)$, lipids 
